\title{
Article \\ FOLFOX Therapy Induces Feedback Upregulation of CD44v6 through YB-1 to Maintain Stemness in Colon Initiating Cells
}

\author{
Shibnath Ghatak ${ }^{1,2}$, Vincent C. Hascall ${ }^{3}$, Roger R. Markwald ${ }^{1}$ and Suniti Misra ${ }^{1,2, *}$ \\ 1 Department of Regenerative Medicine and Cell Biology, Medical University of South Carolina, \\ Charleston, SC 29425, USA; ghataks852@gmail.com or ghatak@musc.edu (S.G.); \\ markwald@musc.edu (R.R.M.) \\ 2 Hollings Cancer Center, Department of Biochemistry and Molecular Biology, Medical University of South \\ Carolina, 86 Jonathan Lucas St, Charleston, SC 29425, USA \\ 3 Department of Biomedical Engineering/ND20, Cleveland Clinic, Cleveland, OH 44195, USA; hascalv@ccf.org \\ * Correspondence: sunitimisra1972@gmail.com or misra@musc.edu; Tel.: +1-843-300-7751
}

Citation: Ghatak, S.; Hascall, V.C.; Markwald, R.R.; Misra, S. FOLFOX Therapy Induces Feedback

Upregulation of CD44v6 through YB-1 to Maintain Stemness in Colon Initiating Cells. Int. J. Mol. Sci. 2021, 22, 753. https://doi.org/10.3390/ ijms22020753

Received: 16 December 2020

Accepted: 9 January 2021

Published: 13 January 2021

Publisher's Note: MDPI stays neutral with regard to jurisdictional clai$\mathrm{ms}$ in published maps and institutional affiliations.

Copyright: $\odot 2021$ by the authors. Licensee MDPI, Basel, Switzerland. This article is an open access article distributed under the terms and conditions of the Creative Commons Attribution (CC BY) license (https:// creativecommons.org/licenses/by/ $4.0 /)$.

\begin{abstract}
Cancer initiating cells (CICs) drive tumor formation and drug-resistance, but how they develop drug-resistance characteristics is not well understood. In this study, we demonstrate that chemotherapeutic agent FOLFOX, commonly used for drug-resistant/metastatic colorectal cancer (CRC) treatment, induces overexpression of CD44v6, MDR1, and oncogenic transcription/translation factor Y-box-binding protein-1 (YB-1). Our study revealed that CD44v6, a receptor for hyaluronan, increased the YB-1 expression through PGE2/EP1-mTOR pathway. Deleting CD44v6, and YB-1 by the CRISPR/Cas9 system attenuates the in vitro and in vivo tumor growth of CICs from FOLFOX resistant cells. The results of DNA:CD44v6 immunoprecipitated complexes by ChIP (chromatinimmunoprecipitation) assay showed that CD44v6 maintained the stemness traits by promoting several antiapoptotic and stemness genes, including cyclin-D1, BCL2, FZD1, GINS-1, and MMP9. Further, computer-based analysis of the clones obtained from the DNA:CD44v6 complex revealed the presence of various consensus binding sites for core stemness-associated transcription factors "CTOS" (c-Myc, TWIST1, OCT4, and SOX2). Simultaneous expressions of CD44v6 and CTOS in CD44v6 knockout CICs reverted differentiated CD44v6-knockout CICs into CICs. Finally, this study for the first time describes a positive feedback loop that couples YB-1 induction and CD44 alternative splicing to sustain the MDR1 and CD44v6 expressions, and CD44v6 is required for the reversion of differentiated tumor cells into CICs.
\end{abstract}

Keywords: CD44v6; YB-1; MDR1; CIC; stemness genes; CD44v6 CRISPR/Cas9 knockout; YB-1 CRISPR/Cas9 knockout; CD44v6-therapy; colorectal cancer (CRC)

\section{Introduction}

Colorectal cancer (CRC) is the second leading cause of cancer-related deaths in Western countries including the USA, with incidences increasing by $2 \%$ annually and has a dismal prognosis with a $14 \% 5$-year survival rate of patients with metastasis $[1,2]$. Recent developments in cancer prevention endeavors, including the extensive application of colonoscopy and the identification and removal of precancerous lesions, have resulted in a considerable overall reduction in CRC incidence [3-5]. Conventional treatment for CRC includes the multicomponent drug FOLFOX that is composed of 5-fluorouracil (5-FU), oxaliplatin (OXA), and leucovorin. FOLFOX chemotherapy is widely used as a first-line chemotherapeutic agent which often fails because the targeted cancer cells acquire chemoresistance over time [6-8]. Even though the prognosis response rate to OXA is approximately $24 \%$, acquired resistance progresses in nearly all patients after repeated treatment with either OXA alone, or with FOLFOX, eventually limiting its therapeutic efficacy $[6,9]$. Improved understanding of the mechanisms that contribute to acquisition of FOLFOX resistance by CRC cells is imperative for developing novel therapies to improve FOLFOX efficacy. 
An important step in understanding mechanisms of cancer drug resistance in recent years, has been a growing body of evidence that tumor tissue is composed of heterogeneous, hierarchy of cells that differ in morphology, gene expression, proliferative capacity, and invasiveness [10]. This heterogeneity originates from a small subset of cancer cells, called cancer stem cells (CSCs) or cancer initiating cells (CICs), that are the unique source of all tumor cells and responsible for tumor propagation and relapse [11]. Interactions between tumor cells and their microenvironment create niches that promote CIC survival. Moreover, when this niche is disrupted, CICs initiate a series of cellular processes for self-renewal, replication, and differentiation in an effort to restore the tumor mass and its microenvironment [12-14]. Since the first identification of CSCs/CICs in breast cancer used a CD44/CD24 marker [15], CICs have been identified in a variety of solid tumors [16-24], including colon carcinomas [25-27]. Unlike naturally occurring somatic stem cells, CICs initiate tumorigenic activity when transplanted into animals [28,29]. Moreover, variation in the genetics and epigenetic damages of CRC patients is so different that markers to detect CICs from more differentiated progeny have not been completely informative across all patient tumors [30-32]. In addition, most CIC enhancement markers mediate interactions between a tumor cell and its stromal environment, indicating that the tumorigenic characteristics associated with that marker may be lost after depletion of CICs from their microenvironment. Similarly, human pancreatic CICs expressing the marker CD133 and the chemokine SDF-1 receptor CXCR4 lost their metastatic activity when the CXCR4 $4^{+} / \mathrm{CIC}$ population was depleted. This implies that CICs may take over information associated with the marker (in this case, SDF-1/CXCR4-controlled pathways) to initiate metastasis [33]. CRC cells expressing CD166 [34], CD44 [35], CD44v6 [27], CD66c [34], CD133 [36], and aldehyde dehydrogenase (ALDH1) [37] describe CIC characteristics. However, the cell-surface markers that recognize CICs and have a functional role in the antiapoptotic signaling to drive tumorigenesis have remained poorly defined.

Our working hypothesis for this study is that CICs are involved in the development of drug-resistance, treatment failure, and tumor relapse in cancer $[38,39]$. We base this hypothesis on observations that CICs acquire high levels of antiapoptotic proteins, possess low levels of reactive oxygen species, and demonstrate an enhanced efficiency of DNA damage repair [36,40,41]. Irrespective of the marker used, CICs are the parental source for which all other malignant cells within a given tumor arise and are responsible for CRC tumor growth/maintenance, metastatic spread, resistance to conventional chemotherapies, and relapse after cancer therapy [11,42]. Therefore, CRC CICs must be effectively targeted to inhibit tumor growth and improve survival of patients with CRC. Our findings indicate that one mechanism for targeting them is to modulate the expression of a splice variant of CD44.

CD44 is a multistructural and multifunctional transmembrane glycoprotein that acts as a receptor for hyaluronan (also called hyaluronic acid). CD44 is encoded by a single gene containing 20 exons, 10 of which are alternatively spliced to generate the numerous CD44 splice variants (CD44v) [43,44]. The standard isoform of CD44 (CD44s) is small with no variant exons and is nearly ubiquitous on vertebrate cells [45]. Variant 6 of CD44 (CD44v6) participates in tumor development and progression in many ways that are restricted to stem cell subpopulations $[27,46]$. In agreement with this, CD44v6, but no other variants, promotes generation of gut adenomas (tumors) in mouse models of familial adenomatous polyposis $[47,48]$. Its role in CRC progression derives from its ability to bind ligands associated with both tyrosine kinase receptors or non-tyrosine kinase receptors including c-Met, VEGF, TGF $\beta 1$, and ERB2 [48-58], leading to changes in biological activities such as activation of antiapoptotic signaling, cell-matrix adhesion, cell migration, proliferation, differentiation, and survival $[59,60]$. Much progress has been made in the assessment of the molecular structures and functions of the standard isoform (CD44s) and of its various isoforms in cancer cell signaling in general rather than by analysis of CIC signaling. Recent studies indicate that CD44 variants are restricted to CIC populations and promote tumor development in animals [61]. CD44v6 positive $(+) / \mathrm{CICs}$ have been associated with increased 
metastatic behavior in both pancreatic cancer $[33,44,62,63]$ and CRC $[27,46]$, suggesting that $\mathrm{CICs}$ may takeover CD44v6-regulated apoptosis resistance-signaling pathways to initiate drug-resistance. Experiments using knock-in mice that express either CD44v4-10 or CD44s isoforms have demonstrated that CD44v isoforms, but not the CD44s isoform, promote adenoma formation in Apc (Min/+) mice [47]. Thus, CD44v6 predicts poor prognosis and is a marker of constitutive and reprogrammed CICs that drive CRC metastasis [27].

Although CICs and somatic stem cells exhibit similar transcription factors (TFs), including SOX2, OCT4, NANOG, KLF4, and c-Myc, several studies have demonstrated that the abnormal expression of some distinctive TFs [64] have a crucial role in the reprogramming of these cells [65]. In this case, overexpression of TFs results in dysregulation of associated signaling pathways that are linked with CIC lineage and differentiation phenotype [66]. Transcriptional regulation occurs when certain TFs bind to the DNA at binding sites of a promoter and affect the transcription of the regulated gene via interactions with their gene promoters $[65,66]$. In this circumstance, TFs may have a crucial role in the maintenance of CIC stemness. Transcription factor networks can be involved in gene regulatory networks $[67,68]$, and dictate cell phenotypes when expressed in various settings in an ectopic manner [69-71]. Several core transcription factors, including TWIST1, Snail, Zeb $1[72,73]$ as well as OCT3/4 [74,75], SOX2 [76], and NANOG [77,78] have pivotal roles in maintenance of pluripotency in both early embryos and embryonic stem cells, adult stem cells, and CICs. In addition, induced pluripotent stem cells (iPSC) can be directly generated from fibroblast cultures by the addition of some of these core TFs [79]. Besides this, several genes that are frequently upregulated in tumors, such as STAT3 $[80,81]$ and $\beta$-catenin $[82,83]$, have been shown to contribute to the long-term maintenance of the stem cell traits. CRC CICs exhibit characteristics comparable to normal stem cells that could be associated with the expression of similar TFs including SOX2, OCT4, NANOG, KLF4, Lgr5, TWIST1, and c-Myc, and signaling pathways including WNT/ $\beta$-catenin pathways directed for CRC propagation $[65,84,85]$. Many studies indicate that the Y-box-binding protein-1 (YB-1) transcription factor can function as an oncoprotein [86-88] to regulate stemness, drug-resistance and tumorigenic properties in various cancers [89-94] including CRC [95]. As mentioned above, CD44v6, a marker of CICs, drives CRC metastasis [27]. A recent study shows that $\mathrm{YB}-1$ binds to the $\mathrm{CD} 44$ promoter to transcriptionally upregulate its expression in breast cancer [96]. PGE2 was shown to induce YB-1 expression, which is involved in the drug resistance and malignance of several carcinomas [97-99]. While we and others have shown that CD44 regulates MDR1 expression in various cancers $[49,100,101]$ and controls COX2-PGE2 signaling in CRC [50,102], whether YB-1 may be linked to the ability of CD44v6 to induce the expression of genes linked to stemness and drug resistance in CD44v6+CICs is not known. Therefore, this study was designed to assess our hypothesis that FOFOX-induced CD44v6/COX2-PGE2/mTOR may promote CRC resistance through upregulation of YB-1 signaling that promotes CD44v6 splicing, and that CD44v6 then sustains YB-1 signaling. The novelty of our results in this study is that it provides the first demonstration of a positive feedback loop linking signaling-dependent alternative splicing of CD44 to the drug-resistance gene MDR1 through YB-1. Further, our results revealed for the first time that $\mathrm{CD} 44 \mathrm{v} 6$ regulated $\mathrm{YB}-1$ signaling is required for the maintenance of FOLFOX resistance and for the reversion of differentiated CD44v6 knockout-CICs into CICs with stemness traits.

\section{Results}

2.1. Upregulation of CD44v6 and $Y B-1$ Contributes to Acquired Chemoresistance and Stemness in Colon Cancer SW948 Cells

To determine the mechanism of FOLFOX resistance in CRC, we developed a cellular model of FOLFOX resistance. We screened seven CRC cell lines for CD44v6 expression and selected few of them including SW948 cells that exhibited lower steady-state expression of CD44v6 (Supplemental Figure S1A). In order to determine the mechanism of FOLFOX (combination of 5-Fluorouracil (5-FU) + Oxaliplatin (OXA) + leucovorin) resistance in CRC cells, we determined the $\mathrm{IC}_{50}$ values of 5-FU and OXA for inhibiting SW948 CRC 
cell growth using a cell viability assay (assessed by ATP based assay (Cell Titer-Glo)) in the presence of increasing concentrations of these chemotherapeutic drugs. The average $\mathrm{IC}_{50}$ value for 5 -FU of SW948 cell is $\approx 60 \mu \mathrm{g} / \mathrm{mL}$, and the average $\mathrm{IC}_{50}$ value for OXA in these cells is $\approx 5-10 \mu \mathrm{g} / \mathrm{mL}$ (Supplemental Figure S1B,C). The average $\mathrm{IC}_{50}$ value for FOLFOX is shown in Supplemental Figure S1D. Next, we evaluated the kinetics of CD44v6 induction upon exposure to $1 \times$ FOLFOX $\left(1 \times\right.$ FOLFOX $=\mathrm{IC}_{50}$ of 5 -FU $+\mathrm{IC}_{50} \mathrm{OXA}+1$ $\mu \mathrm{M}$ leucovorin). Resistance from either 5-Fluorouracil (5-FU) or Oxaliplatin (OXA), two components of FOLFOX, has been associated with increased CD44v6 mRNA expression in CRC cells [103].Thus, in order to determine whether FOLFOX resistance is associated with CD44v6, serum depleted SW948-S cells were stimulated by addition of $1 \times$ FOLFOX in media.

We first examined the expression profile of CD44 variants in SW948 cells after stimulation with FOLFOX by exon-specific reverse transcription-PCR (RT-PCR) analysis (Figure 1A). Several variant isoforms are indeed expressed. Exon v6 seems to be expressed together with exons $v 6-v 8$ and also as an independent isoform (shown in Figure 1A). The expression levels of CD44 variants were examined by RT-PCR using different sets of primers (Figure 1A). The variants were detected using a $5^{\prime}$ primer from a constitutive exon 5 of CD44 and two distinct $3^{\prime}$-primers complementing to $\mathrm{v} 6$, and $\mathrm{v} 8$ exons of CD44, respectively. In addition, the $\mathrm{CD} 44 \mathrm{~s}$ standard form having no alternate splicing was detected using primers for the constitutive exons 5 and 6 of CD44. The CD44v6 primers and CD44s primers each principally amplified a single product (Figure 1A). The v8 primer gave rise to three alternately spliced variants of CD44 containing (1) variant exons v6, v7, and v8 (illustrated as v6-v8); (2), variant exons v3 and v8 (illustrated as v3.v8); (3) and variant exon v8 (shown as v8), all joined to the $5^{\prime}$-constitutive exon 5 (Figure 1A). All products were confirmed by DNA sequencing as described [58]. Following $24 \mathrm{~h}$ of serum starvation, the relative expressions of CD44 variants were low, while stimulation with FOLFOX upregulated v6 mRNA expression that peaked between 4 and $16 \mathrm{~h}$ and returned to basal levels at 24-48 h likely due to the exhaustion of FOLFOX within the media (Figure 1B; primers are in Supplemental Table S1).

To explore whether the induction of CD44v6 expression by FOLFOX was not modulated by various stress environments such as ischemic, or hypoxic, or oxidative stress conditions, we examined the expression of CD44v6 in SW948 cells by treating them with various chemical agents for $48 \mathrm{~h}$. To create ischemic, and/or oxidative stress conditions, we cultured the cells in serum-free medium. For hypoxic stress we employed low-pH condition, $300 \mu \mathrm{M}$ $\mathrm{CoCl} 2$ and for creating oxidative stress, we used $300 \mu \mathrm{M} \mathrm{H}_{2} \mathrm{O}_{2}$. In addition, for chemotherapeutics induced cytotoxic stress, we used $60 \mu \mathrm{M}$ 5-FU, or 5-10 $\mu \mathrm{M}$ OXA ( $\mathrm{IC}_{50}$ of 5-FU (Supplemental Figure S1B), and IC 50 of OXA for SW948 cells (Supplemental Figure S1C), respectively) as well as $1 \times$ FOLFOX in culture medium. CD44v6 expressions were determined using QPCR analysis. Our data demonstrated that basal CD44v6 expression was very low in SW948 cells but significantly increased with chemotherapeutics (5-FU, or OXA, or FOLFOX), whereas stress creating chemical agents did not induce CD44v6 expression (Figure 1C). Similar results were found in HT29 cells (Figure 1C). Overall, our data indicate that in CRC cells (SW948 and HT29 cells), FOLFOX and its components 5-FU and OXA considerably and distinctively induced CD44v6 expression, which could interact with various cellular targets and offer one of the fundamental mechanisms for the drug resistance in CRC cells. 


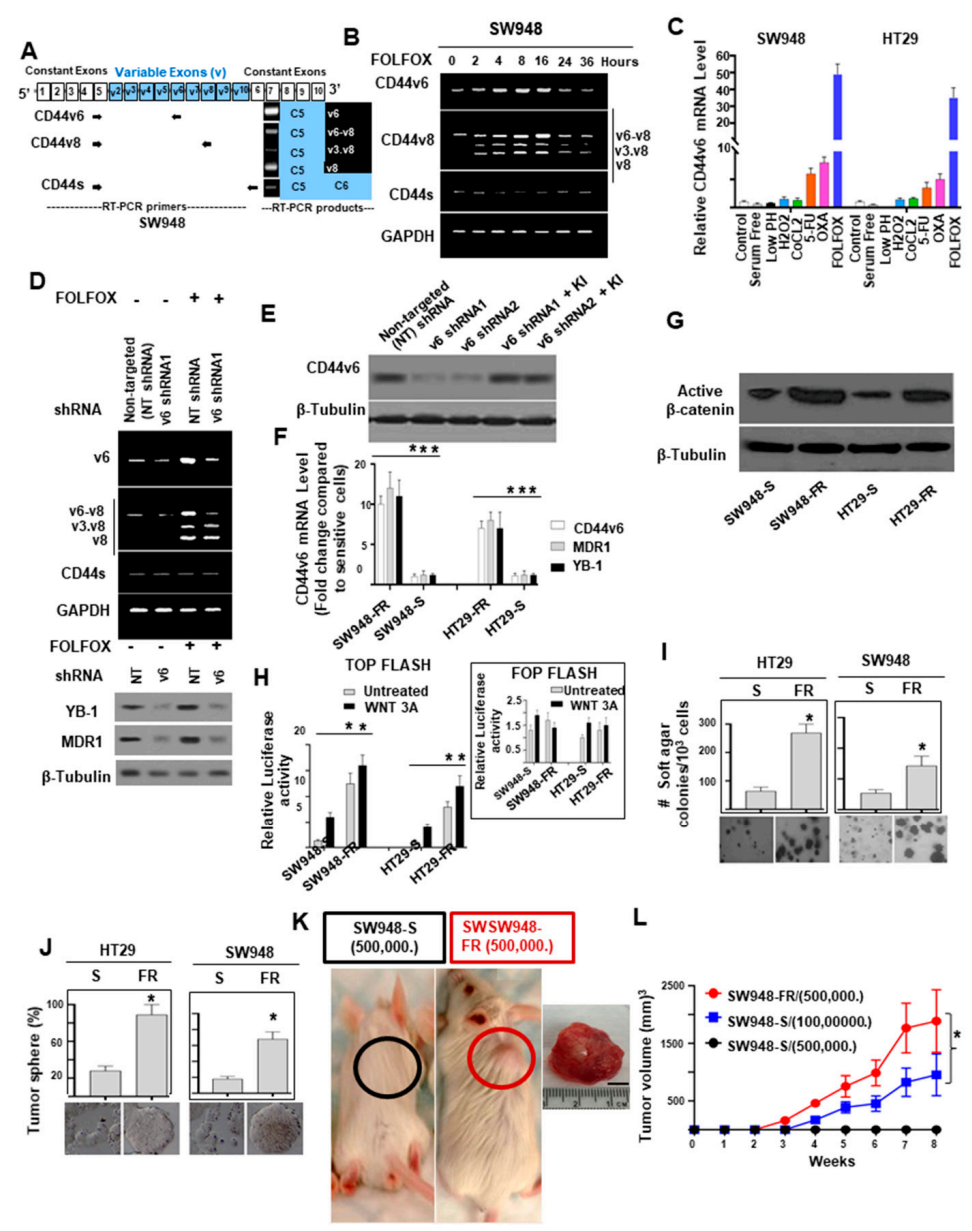

Figure 1. Establishment of FOLFOX resistant colorectal cancer (CRC) cells that exhibit increased CD44v6 expression and signaling. (A) A schematic diagram of the CD44 gene, where constitutive (c) and variable (v) exons, and the PCR primers used to amplify CD44 variable (v) and standard (s) isoforms are shown. The primers for both the CD44v6 and CD44s predominantly generate one PCR product, whereas the primers for the CD44v8 variants amplify three variant PCR products. (B) A time course of FOLFOX (FOLFOX: $50 \mu \mathrm{g} / \mathrm{mL}$ 5-Flurouracil $+10 \mu \mathrm{M}$ Oxaliplatin $+1 \mu \mathrm{M}$ leucovorin) stimulation on CD44 isoform mRNA expressions (analyzed by semiquantitative RT-PCR) in SW948 cells was depicted. (C) QPCR assays for variant 6 of CD44 (CD44v6) expression under low-pH (ischemic stress), $\mathrm{CoCl} 2$ (hypoxic stress), $\mathrm{H} 2 \mathrm{O} 2$ (oxidative stress), 5-FU, OXA, and FOLFOX treatment (chemotherapeutic stress) in SW948 cells are shown. (D) shRNA-mediated knockdown of CD44v6 affects alternative splicing of CD44 and downregulates YB1 and MDR1 expression. (E) Validations of CD44v6 shRNAs were done by the indicated shRNA mediated knockdown and the corresponding shRNA resistant knock-in (KI) gene overexpression. (F) SW948-FR and HT29-FR cells selectively overexpressed CD44v6, MDR1, and YB-1 mRNAs (by QPCR) compared to sensitive ("S") pairs of cells. The expression of indicated proteins in FR cells compared to sensitive pairs are presented as mean $\pm \mathrm{SD}(n=3) ;{ }^{*}, p<0.01$. Student's $t$ test was used to assess the significance. The experiment was performed three times and representative data are shown. (G) Western blot (WB) analyses for $\beta$-catenin and $\beta$-tubulin of "S" and "FR" cell lysates of SW948 and HT29 cells are shown. (H) $\beta$-catenin luciferase activity of "S" and "FR" lysates of SW948 and HT29 cells treated with or without WNT 3A are shown. The relative luciferase in FR cells compared to sensitive pairs are presented as mean $\pm \mathrm{SD}(n=3) ;{ }^{*}, p<0.01$. Student's $t$ test was used to assess the significance. The experiment was performed three times and representative data are shown. (I) Anchorage-independent growth in soft agar is shown for SW948-FR and HT29-FR cells and compared with their "S" pairs (magnification, $50 \times$ ). (J) Tumor-sphere formation assay was done for the SW948-FR and HT29-FR cells and compared with their "S" pairs (magnification, 100×). (K,L) Tumor formation is shown in nude mice injected with 500,000 SW948-FR cells or with 500,000 SW948-S cells. SW948-FR cells formed tumor nodules in all injected mice (8/8), whereas SW948-S cells did not induce any tumor nodules until 5 months (left, 0/7 mice) (K). Growth curves are shown for these xenograft tumors in BALB/c nude mice (L). Values in C, I, and J represent means $\pm \mathrm{SD} ; n=3-6 ;{ }^{*} p<0.05$ for FOLFOX resistant cells compared to sensitive cells. Scale bar, $50 \mu \mathrm{m}$. 
Resistance to chemotherapeutics has been independently associated with increased CD44v6 expression [26,27], and YB-1 overexpression has already been reported to be associated with possible chemoresistance through the regulation of MDR1 in breast cancer [99] and multiple myeloma cells [104]. Therefore, we postulated that CD44v6 and YB-1 may be associated to FOLFOX resistance in SW948 cells. To address this, we evaluated the effects of FOLFOX on protein expressions of YB-1 and the ATP-binding cassette subfamily B member 1 (ABCB1), also known as multidrug-resistance-1 (MDR1), protein expressions in SW948 cells following treatment with or without FOLFOX and CD44v6 shRNA. Knockdown of CD44v6 in SW948 cells downregulated both YB-1 and MDR1 protein expressions and inhibited the FOLFOX-induction of v6-containing variants but not CD44 standard (CD44s), v3.v8 or v8 variants (Figure 1D). Validations of CD44v6 shRNA1 and CD44v6 shRNA2 are shown in Figure 1E. Overall, these results indicate that CD44v6 has key roles for YB-1 and MDR1 expressions in response to FOLFOX.

To further determine the mechanism of FOLFOX resistance, we used serially escalated doses of FOLFOX $(1 \times$ FOLFOX- $\times$ FOLFOX) in parent sensitive CRC cells (SW948-S and HT29-S) to generate FOLFOX-resistant (FR) cells. After recovering from $1 \times$ FOFOX, cells were treated with $2 \times$ FOLFOX. The survived cells were then treated with $4 \times$ FOLFOX to delete most of the cell population. After high-dose $5 \times$ FOLFOX treatment, a small number of cells survived and slowly repopulated to form colonies. Finally, FOLFOX-resistant CRC cells were established, and the $\mathrm{IC}_{50}$ values of FOLFOX in SW948-FR and HT29-FR cells were $3.5 \times$ FOLFOX and $2.8 \times$ FOLFOX $(p<0.001$, compared with each parental cell). The response of the SW948-FR and HT29-FR cells to FOLFOX treatment resistance were evaluated using QPCR assay for CD44v6, YB-1 and MDR1 mRNA expressions and compared to their sensitive pairs (Figure 1F). SW948-FR and HT29-FR cells have significantly higher levels of CD44v6, YB-1, and MDR1 expressions compared to their sensitive pairs SW948-S and HT29-S (Figure 1F).

Given that activation of the WNT/ $\beta$-catenin pathway is the hallmark of colorectal cancer initiating cells (CRC-CICs) [27] and because CICs are naturally resistant to chemotherapy through their quiescence, capacity for DNA repair, and $\mathrm{ABC}$ transporter expression [105], we evaluated stemness in FR cells. Figure 1G,H shows that FOLFOX promoted stemness in FR cells via a WNT/ $\beta$-catenin pathway with higher active $\beta$-catenin expression and increased $\beta$-catenin/TCF4 TOP-Flash transcriptional activity. To determine the clonogenicity of FR cells in vitro, we compared their clonal capacity to sensitive pairs employing a soft agar colony formation assay. Compared to parental sensitive cells, FR cells were able to form increased anchorage-independent growth assessed by formation of soft agar colonies (Figure 1I). It has been recently documented that CRC-CICs could be expanded as tumor-spheres [26,27]. Therefore, we investigated sphere-forming activity of both parental and FR cells. Compared with parental sensitive cells, FR cells were able to form significantly greater numbers of tumor-spheres in serum free medium (Figure 1J). Next, to evaluate, whether the effects of FOLFOX resistance offer increased in vivo tumor growth compared to that implanted with the corresponding sensitive cells, we implanted $5 \times 10^{5}$ cells of sensitive and resistant FR cells of SW948 into immunocompromised mice (\# of mice $=7$ for sensitive and \# of mice $=8$ for FR cells implanted xenograft tumor for each of the experiments; $n=3$ experiments). In agreement with the soft agar growth and tumor sphere formation results (Figure 1I,J), $5 \times 10^{5}$ resistant cells generated tumors in at least $90-100 \%$ of immunocompromised mice injected from SW948-FR cells (Figure 1K, red, tumor formation $=8 / 8$ mice), whereas $5 \times 10^{5}$ sensitive cells (SW948-S) were not adequate to form tumors (Figure $1 \mathrm{~K}$, black, tumor formation $=0 / 7$ mice). However, implantation of 20-fold more sensitive SW948-S cells $\left(1 \times 10^{7}\right)$ were able to initiate tumors in three independent experiments. When tumor volumes were examined every day to evaluate the latency, tumors initiated from $5 \times 10^{5} \mathrm{SW} 948$-FR cells began to increase at 2 weeks while tumors initiated from $1 \times 10^{7}$ SW948-S cells began to increase later at 3-4 weeks and had much smaller size at 8 weeks $\left(900 \mathrm{~mm}^{3}\right.$ compared to $1800 \mathrm{~mm}^{3}$ at 8 weeks, Figure $1 \mathrm{~L}$ ). The results from Figure 1G-L provide evidence that FOLFOX-resistant FR cells were more tumorigenic 
in vitro and in vivo and had greater sphere-forming activity than parental sensitive cells, which are hallmark characteristics of CRC-CICs. This suggests that expansion of CICs might have an important role for the acquisition of FOLFOX resistance.

\subsection{Expansion of CD44v6 (+) CICs during Acquisition of FOLFOX Resistance}

Given that FOLFOX maintained the stemness feature of CRC cells (Figure 1F-K), CICs were isolated from the freshly dissociated subcutaneous tumors (SQ) from the sensitive and resistant cells of SW948 and HT29 by FACS sorting using several of the previously reported candidate markers (CD44v6, CD133, EpCAM, and ALDH1) [14,27,35,106,107]. First, we isolated EpCAM+/Ecadherin- cells by FACS analysis. These cells were then sorted for CD44v6+ / ALDH1+ cells which were further sorted for CD44v6+/ALDH1+/CD133+ CICs by flow cytometry. Our data show that CD44v6+/CICs overlapped with cells that also expressed the epithelial marker EpCAM, and with CIC markers ALDH1 and CD133 antigen expressions in SW948-FR/SQ cells (Figure 2A-C). In agreement with the results of Figure 1D, which showed that CD44v6 regulated YB-1, we found the colocalization of CD44v6 and YB-1 in the SW948-FR/CICs (Figure 2D). The data in Figure 2E indicate that resistant cells enriched CICs coexpressing CIC markers (EpCAM, CD44v6, ALDH1, and CD133) compared to their sensitive pairs. The coexpression of EpCAM, CD44v6, ALDH1, and CD133 in CICs was validated in four independent samples (Figure 2E). Figure $2 \mathrm{~F}$ validates the expression of marker proteins in non-CICs and CICs. Collectively, these data in Figure 2 provide evidence that CICs can be prospectively identified and characterized in the CD44v6 (+) CIC cell population, whereas non-CICs are CD44v6 (-) populations, and that CICs coexpress CD44v6 and YB-1, which further validated coregulation of CD44v6 and YB-1 in response to FOLFOX.

\subsection{Generation of CD44v6 and YB-1 Knockout CICs Using the CRISPR/Cas9 System}

To assess the role of CD44v6 and YB- 1 in CICs, the CD44v6 and YB-1 genes were knocked out in SW948-FR/CICs using the CRISPR/Cas9 system that has been reported to efficiently disrupt genes in various organisms [108,109]. CD44s (with no alternate splicing) and CD44v6 regions are shown in different colors (Supplemental Figure S2A). Sequence comparison of human CD44s and the CD44v6 isoform are shown in Supplemental Figure S2B. Guide RNAs (gRNA) for CD44v6 genes were designed at exon 6 of CD44 (Supplemental Figure S2C). We obtained two CD44v6 knockout SW948-FR/CICs clones named CD44v6-Mu1 clone (v6 Mu1) and CD44v6-Mu2 clone (v6 Mu2). To design the gRNA for YB-1 we used exon 1 of YB-1 as described previously [110]. Guide RNAs (gRNA) for YB-1 genes are shown in Supplemental Figure S3A. We obtained two YB-1 knockout SW948FR/CICs clones named YB-1-Mu3 clone and YB-1 Mu4 clone. The data in Supplemental Figures S2D,E and S3B,C demonstrated that the amplified DNA from the gRNA-transfected CICs (v6 Mu1, v6 Mu2, YB-1 Mu3, and YB-1 Mu4) were cleaved into two bands by the T7E1 enzyme (Supplemental Figures S2E and S3C). In contrast, there was no cleaved band for control CICs (Supplemental Figures S2E and S3C). These results indicate that the CD44v6and YB-1-targeting sgRNA/Cas9 expression plasmids were introduced into the genome of SW948-FR/CICs. After the isolation of single cells from the CD44v6 sgRNA- and the YB-1 sgRNA-transfected SW948-FR/CICs, the CD44v6 gene from the CD44v6-mutated CICs (v6 Mu1 and v6 Mu2) and from the YB-1-mutated CICs (YB-1 Mu3 and YB-1 Mu4) were sequenced. DNA sequencing of v6 Mu1, v6 Mu2, YB-1 Mu3, and YB-1 Mu4 cells revealed deletion of the indicated number of bases in both alleles (Supplemental Figures S2F and S3E). Western blotting (Supplemental Figure S2G) and immunofluorescence (Supplemental Figure $\mathrm{S} 2 \mathrm{H}$ ) showed that CD44v6 was completely knocked out in v6 Mu1 and v6 Mu2 cells and YB-1 was completely knocked out in YB-1 Mu3 and YB-1 Mu4 cells (Supplemental Figures S3D,F). The data in Supplemental Figures S2 and S3 confirmed that CD44v6 and YB-1 knockout SW948-FR/CICs were generated. 


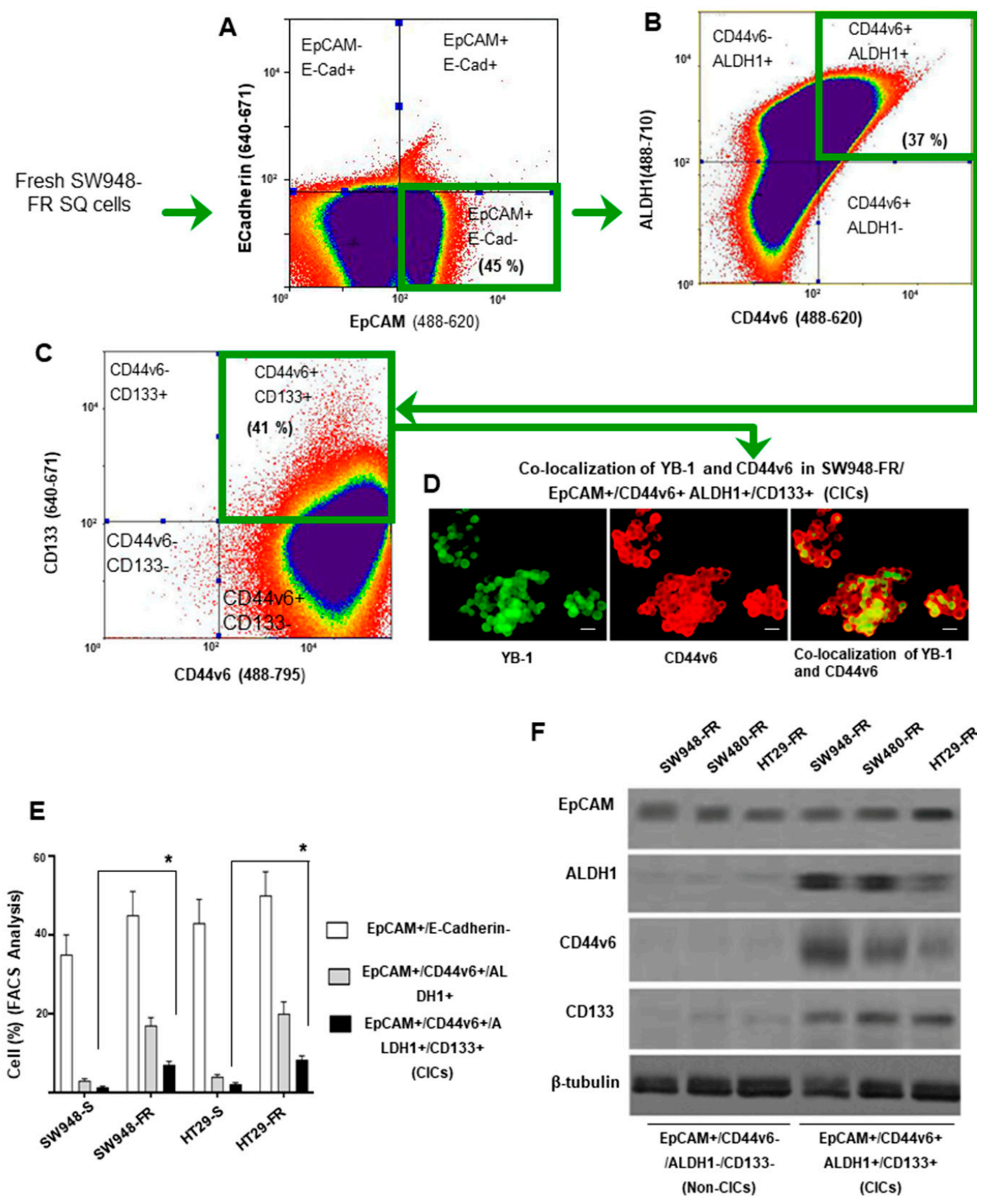

Figure 2. Flow cytometric analyses of EpCAM+/CD44v6+/ALDH+/CD133+ cells in SW948-FR cells isolated from SW948-FR/subcutaneous (SQ) tumors. Alexa fluor-tagged antibodies at the indicated laser lines were used to isolate: (A) EpCAM+/ECadherin- cells; (B) CD44v6+/ALDH1+ cells from EpCAM+/ECadherin-cells; (C) CD133+ cells from CD44v6+/ALDH1+ cells. (D) Immunofluorescence staining shows colocalization of CD44v6 (Red) and YB-1 (Green) in EpCAM+/CD44v6+/ALDH1+/CD133+ (CICs), scale bar, 50 m. (E) Percentages of EpCAM+/E-cadherin-, CD44v6+/ALDH1+, and CD44v6+/ALDH1+/CD133+ on sorted cells were assessed by flow cytometry on freshly purified CRC cells isolated from subcutaneous (SQ) SW948-FR tumor cells. (F) Western blots are shown for EpCAM+/CD44v6/ALDH-/CD133- (Non-CICs) and EpCAM+/CD44v6+/ALDH+/CD133+ (CICs) by probing with E-Cadherin, EpCAM, CD44v6, ALDH1, YB-1, and CD133 antibodies. FACS, immunofluorescence and WB data are representative of three experiments. Enrichment of CICs in FR cells compared to sensitive pairs in Figure 2E are presented as mean $\pm \operatorname{SD}(n=3)$; ${ }^{*}, p<0.01$. Student's $t$ test was used to assess the significance. The experiment was performed three times and representative data are shown. 


\subsection{CD44v6 Regulates YB-1 through a PGE2-MTOR Pathway}

Given that shRNA suppression of CD44v6 protein significantly blocked the FOLFOXinduced YB-1 (Figure 1D), and that the involvement of CD44/CD44v6 in regulating COX2 derived PGE2 production [50,102], which in turn regulates YB-1 in other cancer cell types [111], we investigated a possible interconnection between FOLFOX induced CD44v6-PGE2 signaling and YB-1. First, the v6 Mu1 CICs were transfected with a vector expressing a CD44v6 rescue plasmid in order to rescue CD44v6, and then the expression of CD44v6 and its regulation on YB-1 expression were assessed. Protein analysis by Western blot (WB) showed that CD44v6 protein expression was rescued in v6 Mu1 plus v6 WT CICs (Figure 3A). Importantly, the rescue of CD44v6 also rescued substantial levels of expression within 24-36 h (Figure 3A).

Second, to address the mechanism of CD44v6/PGE2 regulation of YB-1 in CICs, we first evaluated how the CD44v6-PGE2 pathway is affected in FOLFOX resistant SW948FR CICs. To address this, the levels of secreted PGE2 in the culture media of v6 Mu1, or v6 wild-type (WT) CICs with or without FOLFOX therapy were examined using an ELISA assay. The results (Figure $3 \mathrm{~B}$ ) show that FOLFOX treatment induced significant secretion of PGE2 in SW948-S CICs, and this induction of PGE2 was significantly decreased in v6 MU1 CICs of SW948-S cells. Similarly, v6 MU1 CICs showed substantial reduction in PGE2 production compared to v6 WT CICs of SW948-FR cells. These data (Figure 3B) indicate that a CD44v6/PGE2 signaling axis may have an important role in FOLFOX resistance.

Third, to further explore the mechanism of CD44v6 regulation of YB-1 in CICs, SW948$\mathrm{S}$ CICs were treated with synthetic PGE2 (17-P-T-PGE2) for the indicated times shown in Figure 3C, and PGE2 greatly increased the expression level of YB-1 with time. This stimulation was apparent after $4 \mathrm{~h}$, peaked at $12-16 \mathrm{~h}$ (Figure $3 \mathrm{C}$, lanes $4-5$ vs. lane 1 ) and decreased to basal level at $24 \mathrm{~h}$ (Figure 3C, lane 6 vs. lanes $4-5$ ) probably due to the depletion of PGE2 in the medium. Importantly, SW948-FR CICs demonstrated constitutively high expression of YB-1 without exogenous addition of PGE2 (Figure 3C, lane 7 vs. lane 1). Next, we found that knockout of CD44v6 protein (v6 Mu1 significantly blocked both the FOLFOX-induced (Figure 3D, lane 4 vs. lane 2) and the PGE2-induced YB-1 expressions (Figure 3D, lane 5 vs. lane 3). These findings indicate that CD44v6 was able to upregulate YB-1 expression through PGE2 in CRC CICs after FOLFOX therapy (Figure 3D, lanes 4 or 5 vs. lanes 2 or 3), or in FOLFOX resistant SW948-FR CICs (Figure 3D, lane 8 vs. 7). Since PGE2/EP1/mTOR promoted YB-1 expression in other cancer cell types [111], we investigated whether PGE2/EP1 receptor and $\mathrm{mTOR}$ are also involved in the CD44v6 induced YB-1 expression in SW948-FR CICs. Figure 3E shows that SW948-FR CICs strongly express YB-1 (lanes 1,2) that is greatly inhibited in v6 Mu1 cells (lane 4 vs. lane 2) and by treatment with EP1 inhibitor AH6809 (lane 3 vs. lane 1), or with mTOR inhibitor PP242 (lane 5 vs. lane1). Moreover, v6 Mu1 SW948-FR CICs treated with EP1 inhibitor AH6809 (Figure 3E, lanes 6 vs. lane 3) or mTOR inhibitor PP242 (Figure 3E, lane 7 vs. lane 5) further inhibited the YB-1 expression more than single treatment (lanes 6, 7 vs. lanes 3,5$)$. These observations indicate CD44v6 regulated mTOR has important roles in YB-1 expression induced by PGE2/EP1 in response to FOLFOX resistance. 
A

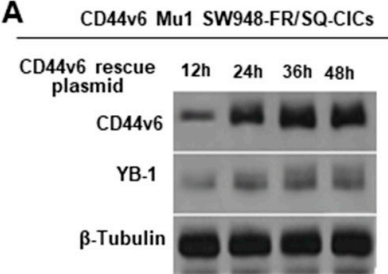

C

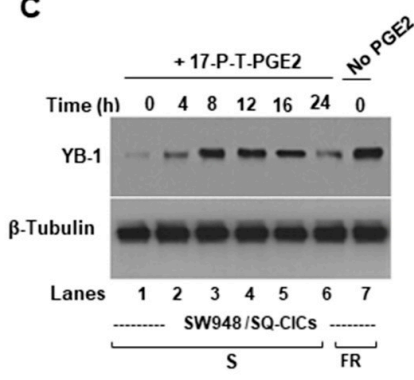

E

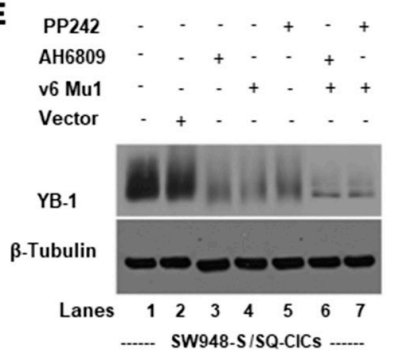

B

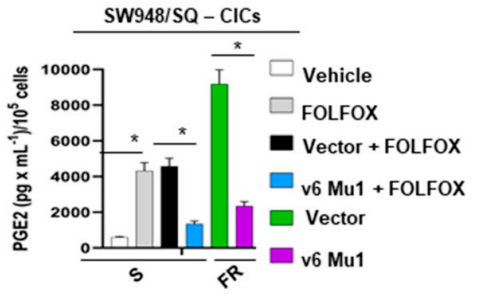

D

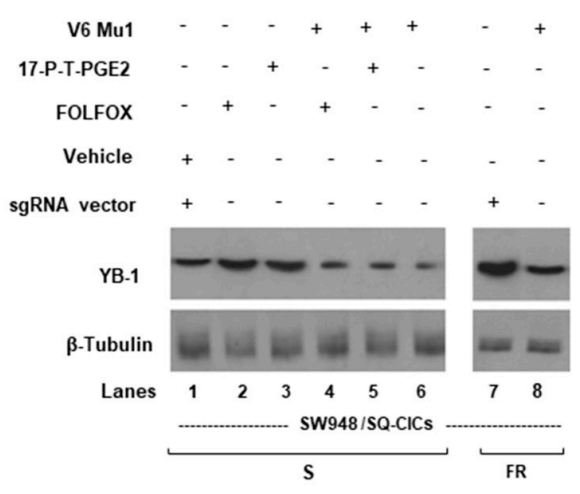

Figure 3. Mechanism of CD44v6 induced YB-1 expression. (A) Time course results are shown of CD44v6 and YB-1 protein expressions after transfecting the v6 rescue plasmid (described in the Methods section) into v6 Mu1 SW948-FR CICs. Expression of proteins at $0 \mathrm{~h}$ was not shown because of the absence of CD44v6 in the protein lysate. (B) Effects of knocking out CD44v6 in in v6 Mu1 CICs of sensitive and resistant SW948 cells on PGE2 production (analyzed by ELISA as described in Methods) in the presence and absence of FOLFOX treatment are shown. (C) 17-P-T-PGE2 (synthetic PGE2) induces YB-1 in CICs that were treated with PGE2 at $5 \mu \mathrm{M}$ for the indicated times. YB-1 expression levels were determined by immunoblotting with anti-YB-1 antibody; $\beta$-tubulin as loading control. (D) Effects are shown of CD44v6 Mu1 knockout on PGE2 and FOLFOX induced YB-1 expression. CICs isolated from SW948-S and SW948-FR that were previously transfected with either v6 Mu1 or vector for $48 \mathrm{~h}$ and then treated with or without synthetic PGE2 or FOLFOX. YB-1 expression levels were determined by immunoblotting with anti-YB-1 antibody; $\beta$-tubulin as loading control. (E) Effects are shown of PGE2/EP1 receptor, and of mTOR signaling on YB-1 expression. CICs were either transfected with in v6 Mu1 or vector for $48 \mathrm{~h}$ and then treated with or without EP1 inhibitor (5 $\mu \mathrm{M}$ AH6809) or mTOR inhibitor (10 nM PP242) for $2 \mathrm{~h}$. They were then cultured in serum-free medium for $16 \mathrm{~h}$ and treated with synthetic PGE2 at $5 \mu \mathrm{M}$, or $1 \times$ FOLFOX for $24 \mathrm{~h}$. The cell lysates were processed for YB-1 and $\beta$-tubulin (as loading control). PGE2 secretion data in Figure 3B represent means \pm SD; $n=4-6 ;{ }^{*} p<0.05$ compared to either vehicle control, vector + FOLFOX treatment group, or vector control group.

\subsection{CD44v6-YB-1 Signaling Defines the Stemness of CICs}

Therapeutic resistance has been reported to be a defining feature of CICs [27,112-114]. A few recent studies have shown that CD44v6, or YB-1 individually stimulate the drugresistance in CRC $[27,95]$. However, the role of CD44v6-YB-1 signaling in stimulating FOLFOX resistance in CRC is unknown. To explore the role of CD44v6 in CICs, the proliferation and viability of v6 WT CICs, v6 Mu1 CICs, and v6 Mu1 CICs plus CD44v6 rescue plasmid, were evaluated. The results of ATP Glo assays revealed that the viability of v6 Mu1 SW948-FR CICs was significantly decreased compared with that of CD44v6 WT SW948-FR CICs (Figure 4A). Rescue of CD44v6 expression in v6 Mu1 CICs led to viability similar to that of v6 WT CICs (Figure 4A). These data indicate that CD44v6 promoted the proliferation of CRC CICs. Next, the cell cycle of CICs was characterized by flow cytometry, 
and the results in Figure 4B show that the percentage of v6 MU1 CICs in G1 phase was significantly increased compared with that of the corresponding WT CICs. Importantly, when the expression of CD44v6 was rescued in v6 MU1 SW948-FR CICs, the percentage of cells in G1 phase was similar to that of wild-type CICs (Figure 4B).

To characterize the influence of v6 Mu1 knockout on the apoptosis of CICs, apoptotic activities of v6 Mu1, v6 WT, or v6 rescue in v6 Mu1 CICs were examined using Annexin V assays by flow cytometry. The results showed that v6 Mu1 led to a significant increase in apoptotic activity in SW948-FR CICs compared with that in v6 WT cells, while apoptotic activity in v6 rescued Mu1 CICs was closely resembling that in v6 WT cells (Figure 4C,D). The Annexin $\mathrm{V}$ data indicated that v6 Mu1 knockout in CICs promoted the apoptosis of CICs (Figure 4C,D).

To explore the mechanism underlying the requirement of CD44v6 for the stemness of CICs, the DNA sequences bound by nuclear CD44v6 complexes were analyzed by ChIP assays in CICs from sensitive and resistant cells of SW948 using a CD44v6specific antibody. DNA fragments bound by nuclear CD44v6 complexes were pulled down by the anti-CD44v6 antibody from a total of 15 clones. A National Center for Biotechnology Information basic local alignment search tool analysis shows that these clones contained sequences/binding elements for transcription factors (TFs) (Figure 4E; (Supplemental Table S2)) associated with 5-motifs (cell-survival, proliferation, anti-apoptosis, invasion, and stemness) containing genes (CyclinD1, BCL2, MMP9, FZD1, and GINS1) (Figure 4F) that are involved in cell survival, cell proliferation, apoptosis resistance, invasion, and stemness in CICs. Moreover, expressions of these TFs were either very negligible or null in sensitive cell CICs compared to resistant cell CICs (Figure 4E). The promoter sequences associated with TFs (Supplemental Table S2) that bound to the CD44v6 protein could be classified into two themes: (1) genes for 5-motifs such as, Cyclin D1 for cell proliferation/apoptosis-resistance/stemness [115], BCL2 for cell survival [115], FZD1 for stemness [116,117], GINS-1 for DNA replication modulation to regulate proliferation in CICs [118], and MMP9 for cell invasion [119]; (2) four core-stemness genes (ALDH1, NANOG, Lgr5 and ABCB1) for drug-resistance and maintenance of stemness of CRC CICs [115]. The quantitative real-time PCR (QPCR) results showed that the mRNA levels of Cyclin D1, BCL2, FZD1, GINS-1, and MMP9 were significantly increased with rescue of CD44v6 expression in v6 Mu1 SW948-FR CICs (Figure 4F), suggesting that the CD44v6 was responsible for the expression of these 5-motifs related genes. Like other cell surface receptors, CD44v6 is known to migrate to the nucleus as an intact polypeptide or as a proteolytic fragment with or without their ligands. Nuclear localized receptors have been shown to act as co-transcription factors to regulate genes like Cyclin D1 [120,121], FGF2 [122], COX2 [123], c-Jun [124], BCL2 [121], CD49f [96], and MMP9 [125] by interacting with various transcription factors including STAT3 [120,121], RUNX2 [125], NFkB [126,127], p300 [121], E2F1 [128], and YB-1 [96,129]. Although other groups showed binding of nuclear CD44 to chromatin [121,125], our study is the first to demonstrate that posttranslational modification of CD44 is required for efficient interaction between nuclear CD44v6 with the multiple transcription factors (E2F1, YB-1, STAT3, NFkB, and RUNX2; (Supplemental Table S2)) to induce Cyclin D1, BCL2, MMP9, FZD1, and GINS1 promoters. Therefore, in this study, we demonstrate that CD44v6 once engaged with YB-1 is translocated to the nucleus, where it binds to various promoters of genes for 5-motiffs (CyclinD1, BCL2, MMP9, FZD1, and GINS1) in order to maintain CIC growth. 


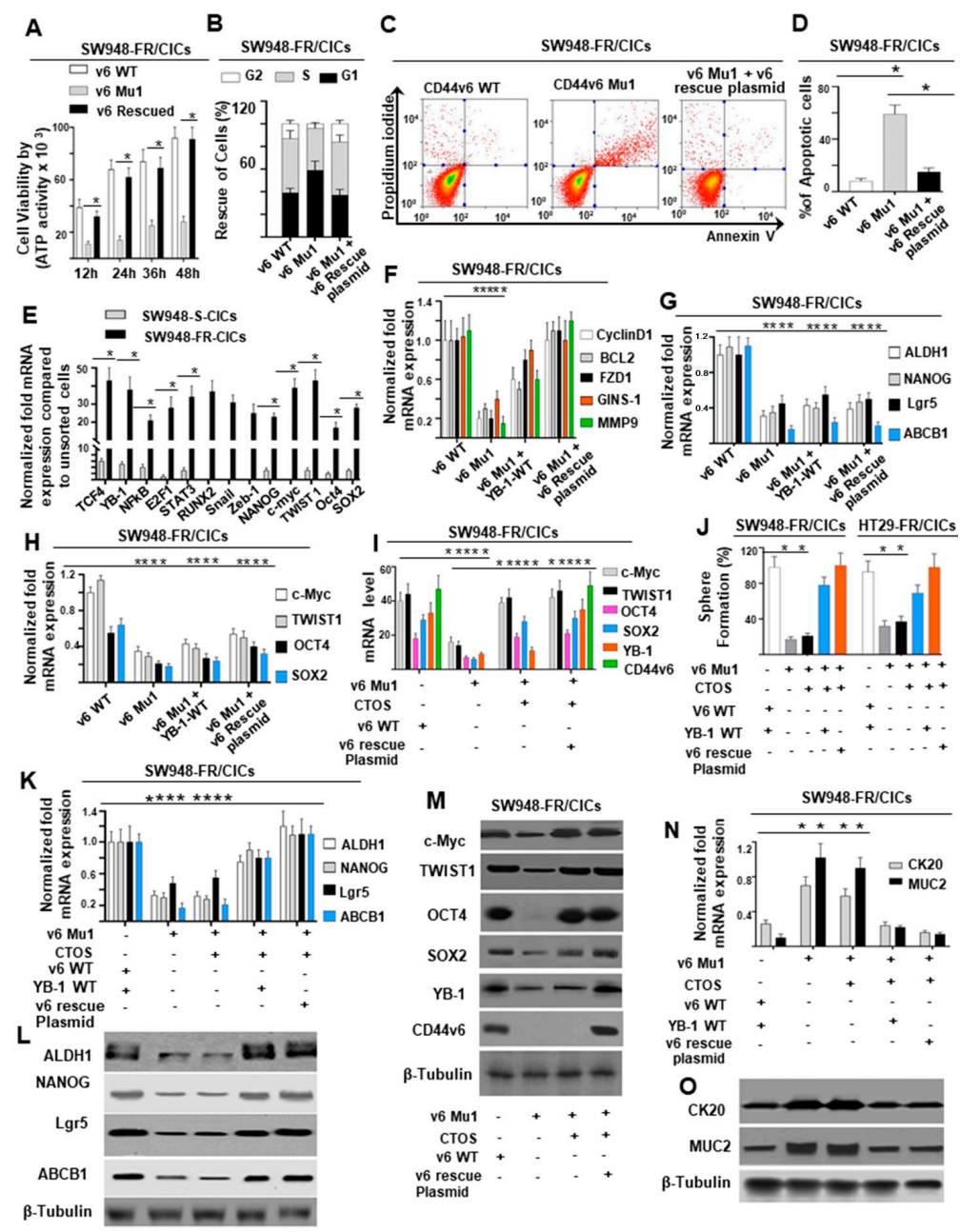

Figure 4. Requirement of CD44v6 and YB-1 for the stemness of SW948-FR CICs after acquisition of FOLFOX resistance. (A) The effects are shown of CD44v6 knockout on cell viability (using ATP Glo method) of CD44v6 Mu1, CD44v6 WT, and on CD44v6-rescue SW948-FR/CICs $\left(1 \times 10^{3}\right.$ cells/well of 96-well plate) which were cultured for the indicated times. The time point $0 \mathrm{~h}$ represents the number of inoculated cells (data not shown). (B) The influence of CD44v6 on cell cycle of CD44v6 Mu1, CD44v6 WT, and CD44v6-rescue SW948-FR CICs are shown. Cells $\left(1 \times 10^{4}\right)$ were cultured for $48 \mathrm{~h}$, and the percentage of cells in G1, S, and G2 phases of cell cycles were examined with flow cytometry. (C,D) Indicated SW948-FR CICs were seeded into a 6-well plate at $1 \times 10^{5}$ cells/well and cultured for $48 \mathrm{~h}$. The extents of apoptosis of CICs in the cultures were examined by flow cytometry. (E) A ChIP assay was performed with chromatin from SW948-FR CICs using an anti-CD44v6 antibody. The immunoprecipitated DNA was amplified by PCR and subcloned. A total of 13 clones were sequenced. Computer-based analysis revealed the presence of various consensus binding sites for common transcription factors in these DNA sequences (see Supplemental Table S2). QPCR analyses show the expressions of these 13 transcription factors in CICs of "S' and "FR" cells of SW948. (F) Expressions are shown for antiapoptosis/stemness-related genes in v6 WT CICs, v6 Mu1 CICs, YB-1 WT overexpressed v6 Mu1 CICs, and in CD44v6 rescue plasmids overexpressed v6 Mu1 CICs. QPCR was conducted to detect the expression levels of the genes. $(\mathbf{G}, \mathbf{H})$ Influence of v6-rescue plasmid into v6 Mu1 CICs for stemness-related gene expressions (G) and stemness-related TFs (c-Myc, TWIST1, OCT4, and SOX2) (H) were measured by QPCR. (I,M) The CD44v6-WT plasmid, or the constructs of the "CTOS" (c-Myc, TWIST1, OCT4, and SOX2) TFs either alone or with CD44v6-rescue plasmid, were transfected into the v6 Mu1 SW948-FR CICs. At $72 \mathrm{~h}$ after transfection, QPCR (I) or Western blot (M) analyses were done to examine the expression levels of these transcription factors. (J,K,L, N,O) Effects of simultaneous expressions of the "CTOS" with the CD44v6-rescue plasmid are shown on sphere formation $(\mathbf{J})$, on the expressions of indicated stemness-related genes and protein $(\mathbf{K}, \mathbf{L})$, and on differentiation-related genes and protein $(\mathbf{N}, \mathbf{O})$ in v6 Mu1 SW948-FR CICs. The experiments were biologically repeated for three times. QPCR data represent means $\pm \mathrm{SD} ; n=4-6$; $p<0.05$ compared to vector control, WT control, or vehicle cell control group. Western blot data are representative of three experiments. 
CICs maintain self-renewal to form matching daughter cells by cell division and differentiate into multilineage cells present within tumors [10]. These differentiated cells differ from their normal counterpart by maintaining their malignancy by expressing tissue-specific stemness-marker protein profiles via various core-stemness associated TFs, which define the phenotype of the cells [71]. Recent studies showed that core-stemness associated TFs, including OCT4, KLF4, SOX2, and c-MYC (also known as OKSM), dictate key functions in gastrointestinal tumorigenesis, by regulating cell migration, metastasis, and resistance to therapy $[79,130,131]$. However, their specific roles in CRC have not been revealed in every aspect so far, particularly with respect to CD44v6 regulation. Of four core transcription factors (CTOS) (c-Myc. TWIST1, OCT4, SOX2), TWIST1 is described to be essential for CRC propagation [85,132], and c-Myc, OCT4, and SOX2 are sufficient to fully reprogram differentiated gastrointestinal cells to gastrointestinal stem cells [133]. In addition, we found that, the DNA:nuclear CD44v6 clones contained cis-regulatory elements c-Myc, TWIST1, OCT4, and SOX2 (Supplemental Table S2), which can define the phenotype of cells of specific tissue, by expressing stemness-related cell surface markers (ALDH1, NANOG, Lgr5, and ABCB1) [84,85,134-136] of CICs. Indeed, QPCR data showed that four (ALDH1, NANOG, Lgr5, and ABCB1) stemness-related genes [84,85,134-136] were significantly downregulated in v6 Mu1 SW948-FR CICs, respectively (Figure 4G). Rescuing the expression of the CD44v6 protein (v6-rescue) did not restore these inhibitions (Figure 4G). Similarly stemness-related TFs (CTOS) (c-Myc [137], TWIST1 [85], OCT4 and SOX2 $[84,138])$ were also downregulated in v6 Mu1 SW948-FR CICs, respectively (Figure $4 \mathrm{H}$ ). These data indicate that these CTOS TFs and the stemness-related genes (ALDH1, NANOG, Lgr5, and ABCB1) as well as CD44v6 were essential for the reversion of differentiated cancer cells.

To restore the differentiated cancer cells into CICs, expression vectors expressing cMyc, TWIST1, OCT4, and SOX2 (CTOS) were separately transfected into v6 Mu1 SW948-FR CICs with or without a v6-rescue plasmid to express these genes and proteins (shown in Figure 4I,M). Consistently, YB-1 is regulated by CD44v6 (Figure 4I,M). The results in Figure $4 \mathrm{~J}$ showed that the tumor sphere formation capacities of SW948-FR CICs or HT29FR CICs were significantly decreased in the absence of CD44v6, even if the CTOS were expressed. Nevertheless, in simultaneous expression of CD44v6 and the CTOS, the tumorsphere forming capacity of v6 Mu1 knockout CICs was comparable to that of wild-type CICs (Figure 4J). Quantitative real-time PCR analysis showed that the expressions of four stemness genes and proteins (ALDH1, NANOG, Lgr5, and ABCB1) were significantly downregulated in v6 Mu1 SW948-FR CICs even when the CTOS were overexpressed (Figure 4K,L). However, the simultaneous expression of CTOS withYB-1 WT plasmid, or CTOS with CD44v6 rescue plasmid promoted the expression of stemness genes and proteins in v6 Mu1 SW948-FR CICs, which was consistent with the results in v6-WT SW948FR CICs (Figure 4K,L). These data indicate that CD44v6 and the other CTOS TFs are capable of reverting the differentiated cancer cells into CICs.

To further evaluate the effects of the CTOS on the dedifferentiation of v6 Mu1 knockout CICs, the expression levels of differentiation genes in CRC (cytokeratin 20 (CK20) and mucin 2 (MUC2) [139]) were examined. The results revealed high expression levels of CK20 and MUC2 genes and proteins in v6 Mu1 CICs (Figure 4N,O). Overexpression of the CTOS in v6 Mu1 CICs generated similar results (Figure $4 \mathrm{~N}, \mathrm{O}$ ). However, with simultaneous expression of CTOS with YB-1 WT plasmid, or CTOS with CD44v6 rescue plasmid in v6 Mu1 CICs, the expression profiles of differentiation (CK20 and MUC2) genes were consistent with those in CD44v6 wild-type CICs (Figure 4N,O). These results indicate that CD44v6 was required for the reversion of differentiated cancer cells into CICs with stemness.

\subsection{Analysis of CIC Stemness Associated Genes and Drug-Resistance Proteins in SP Cells}

Side population (SP) cells are a subset of enriched progenitor cells with CIC-like phenotypes that exhibit the ability to self-renew as well as give rise to differentiated 
tissue cells with a distinct low Hoechst 33342 dye staining pattern [140-142]. In order to determine whether CD44v6 affects the population of CRC cells, we investigated this aspect by flow cytometry.

We isolated v6-Mu1 SW948-FR, and YB-1 Mu3 SW948-FR single clones, and v6 Mu1 plus YB-1 Mu3 SW948-FR single clones targeted by CD44v6-sgRNA (v6 Mu1), YB-1-sgRNA (YB-1 Mu3) expression plasmids. We cultured individual clones each in 96-well plates and allowed them to grow by changing the media $3 \times$ times a week until colonies were formed. After dissociation of single clones, we cultured them in 24-well tissue culture plates, and further cultured them in 6-well plates to get increased cell numbers. These cultures were purified by flow cytometric analysis using a CK (pan)-fluorescein isothiocyanate antibody. Flow cytometric analyses were done with SW948-FR cells after treatment with verapamil, or from v6 Mu1, or YB-1 Mu3 clones. The cells were stained with Hoechst 33342 (Figure 5A,B). The levels of SP cell populations were substantially diminished in the presence of verapamil or from v6 Mu1, and YB-1 Mu3 clones. Our results (Figure 5B) also suggest that a significantly higher population of SP cells were reduced with v6 Mu1 $(0.15 \%)$ compared to YB-1 Mu3 cells $(0.31 \%)$. Purified isolated SP cells and non-SP cells from various sgRNA transfectants of SW948-FR cells were cultured separately and grown in fresh medium for 2 weeks. Afterwards, cultured SP cells and non-SP cells were subjected to flow cytometric analysis using Hoechst 33342 dye again to reanalyze these SP and non-SP populations. The freshly sorted SP were further processed for cell viability/cell proliferation analysis using ATP Glo and clonogenic assays. The data shows that SW948-FR-SP cells demonstrated substantially increased cell proliferation compared to non-SP cells (Figure 5C, $\approx 5$ fold at day 6 ). Consequently, the SP cells were analyzed for FOLFOX-sensitivity in chlonogenic growth assay. The results in Figure 5D show that $1 \times$ FOLFOX sensitizes the non-SP cells (34\% survival) whereas the SP-cells are resistant to apoptosis/death (Figure 5D, 91\% survival), suggesting that the SW948-FR SP cells are highly resistant to FOLFOX.

Results from Figure 5E demonstrate that CD44v6 and YB-1 downregulation sensitizes SW948-FR/SP cells to $1 \times$ FOLFOX and more to $2 \times$ FOLFOX treatment. Knockdown of CD44v6 led to increased cytotoxicity compared to YB-1 Mu3 SW948-FR/SP cells in response to $1 \times$ FOLFOX and to $2 \times$ FOLFOX treatment with reduced colony formation (Figure 5E). The residual colony number after knockdown of CD44v6 and YB-1 (Figure 5E) suggests that in addition to CD44v6 regulation of YB-1, YB-1 may also be regulated by other signaling. Thus, CD44v6-YB-1 signaling activity mediates FOLFOX resistance in resistant SP cells.

A recent study demonstrated that overexpression of the drug resistant transporter contributes to Hoechst dye expulsion and the drug-resistance properties of SP cells in solid tumors including CRC cells expressing stemness genes $[143,144]$. We analyzed the stemness gene expressions of ALDH1, NANOG, LGR5, ABCB1, as well as CD44v6 in SP and non-SP cells from the SW948-FR cells. QPCR analysis revealed that these stemness genes were more highly expressed in SP cells than in non-SP cells (Figure 5F). Subsequently, mRNA analysis revealed that the protein expression of cell proliferation/apoptosis-resistance/stemnessrelated genes (CyclinD1, BCL2, FZD1, GINS-1, MMP9, and MDR1) were significantly decreased in v6 Mu1 SP cells (Figure 5G). To further evaluate the role of the dedifferentiation of non-SP cells versus differentiation of SP cells, the expression levels of differentiation genes (CK20, MUC2) in SP and non-SP cells of SW948-FR cells were examined. The results revealed high expression levels of these differentiation genes in non-SP cells compared to SP cells (Figure $5 \mathrm{H}$ ). These findings clearly demonstrate that elevated expression of CD44v6, YB-1, and MDR1 (ABCB1) as well as other stem cell and antiapoptotic genes/proteins are likely responsible for the FOLFOX apoptotic resistance, self-renewal capacity, and rapid proliferation, and for the reversion of differentiated cancer cells into CICs. 


\subsection{Nuclear YB-1 Associates with CD44v6 and Functions to Modulate CD44v6 and} MDR1 Transcription

A recent study demonstrated that $\mathrm{YB}-1$ regulated CD44 in primary breast cancer cells [96]. Moreover, YB-1 also regulates MDR1 in primary breast cancer cells [99]. To understand the mechanism of YB-1-CD44v6 regulation, chromatin immunoprecipitation (ChIP) was done to identify DNA sequences bound by nuclear CD44v6 complexes. DNA fragments were pulled down by anti-CD44v6 antibody from a total of 15 clones. A National Center for Biotechnology Information basic local alignment search tool analysis shows that these clones contained sequences (Supplemental Table S2) corresponding to the promoters of several genes, including $\beta$-catenin. Among them, 13 clones contained sequences for YB-1. Thus, we tested whether nuclear $\mathrm{CD} 44 \mathrm{v} 6$ exerts its transcriptional regulatory function on MDR1 through interacting with YB-1. Coimmunoprecipitation (Co-IP) showed nuclear colocalization of CD44v6 and YB-1 in unstimulated SW948-FR and FOLFOX stimulated SW948-S nuclear extracts (Figure 6A). Our data also showed that very little CD44v6 and YB-1 were associated with YB-1 immunoprecipitates (IPs) of nuclear extracts of SW948-S cells, whereas elevated expressions of CD44v6 and YB-1 were found with YB-1 IP in the nuclear extracts of SW948-FR cells that endogenously express high levels of CD44v6 and YB-1 (Figure 6A). Knocking down CD44v6 in v6 Mu1 CICs significantly suppressed expression of CD44v6 and YB-1 in nuclear lysates of SW948-FR cells (Figure 6A).

To further evaluate the relative contribution of the YB-1 transcription factor to the regulation of MDR1 promoter activity, we performed transient transfection assays using SW948-FR cells with constructs containing YB-1 binding sites within the MDR1 promoter (Figure 6B) cloned into a luciferase reporter plasmid. These PGL3-mdr (1) and PGL3-mdr (2) constructs were transfected with or without manipulations of CD44v6 and YB-1, and luciferase activities were measured. The results showed that luciferase activity increases in the presence of YB-1 binding sites in these SW948-FR CICs (Figure 6C). Even with only one YB-1 binding site in the pGL3-mdr1 (2), the activity was only slightly less than pGL3-mdr (1) with more than one YB-1 binding site (Figure 6C). The MDR1 promoter luciferase constructs negatively responded to cotransfection with v6 Mu1 and YB-1 Mu3 in SW948-FR CICs (Figure 6C). These reductions show that YB-1 promoter binding and activation of MDR1 is mediated through both CD44v6 and YB-1 in the nucleus of SW948-FR CICs.

To identify whether CD44v6 binds to YB-1 binding sites in the MDR1 promoter in SW948-FR CICs, ChIP assays were done. Immunoprecipitated YB-1-, CD44v6-, and IgGchromatin complex and input DNA were amplified using primers (Supplemental Table S3) covering the indicated YB-1 binding sites of the MDR1 promoter (as shown in Figure 6D). Semiquantitative ChIP RT-PCR assays (Figure 6D) showed that YB-1 bound to two MDR1 sites, and expression levels were almost null in sensitive SW948-S cells and significantly increased in resistant SW948-FR cells. CD44v6 only bound to these two sites in resistant cells with markedly increased binding to YB-1 when compared to very less or no association with sensitive cells (Figure 6E). Knockdown of CD44v6 and YB-1 reduced endogenous MDR1 promoter binding to CD44v6 and YB-1 in DNA complexes in SW948-FR CICs (Figure $6 \mathrm{~F}$ ), thus validating our results from luciferase reporter assays that $\mathrm{CD} 44 \mathrm{v} 6$ and YB-1 coregulate MDR1 expression in a CD44v6-regulated manner in FOLFOX resistant SW948-FR CICs.

Several putative YB-1 binding sites were located 2.1 kilobases upstream of the transcriptional start site of the CD44v6 gene (Figure 6G). A fragment of the CD44v6 gene promoter $(-2100$ to $500 \mathrm{bp}$ ) was fused upstream of the firefly luciferase gene in pGL3CD44v6 (1), and similarly in pGL3-CD44v6 (2) it was fused upstream (-1700 to $500 \mathrm{bp}$ ). pGL3-CD44v6 (1) and pGL3-CD44v6 (2) contain YB-1 binding sites. Luciferase assays were used to directly examine the interaction between $\mathrm{YB}-1$ and the $C D 44 v 6$ promoter. The luciferase activities in SW948-FR cells transfected with v6-Mu1 and YB-1 Mu3 SW948-CICs were significantly lower than vector control group, while YB-1 overexpression significantly increased the luciferase activity (Figure $6 \mathrm{H}$ ). This provides evidence that $\mathrm{YB}-1$ increases CD44v6 transcription activity. To validate these results, conventional ChIP analyses were 
done, and they provided direct evidence for the ability of YB-1 to bind to the promoters of CD44v6 (Figure 6I-K). Thus, the results in Figure 6 show that a YB-1 pathway promotes both CD44v6 and MDR1 gene expressions. Overall, the above results indicate that FOLFOX treatment mediates a CD44v6-PGE2-mTOR-YB-1 pathway that promotes CD44v6 expression (Figures 3 and 6 ) and functions through a positive feedback loop between CD44v6 and YB-1 that activates MDR1 gene expression and CD44v6 splicing through noncanonical signaling and thereby mediates FOLFOX resistance.

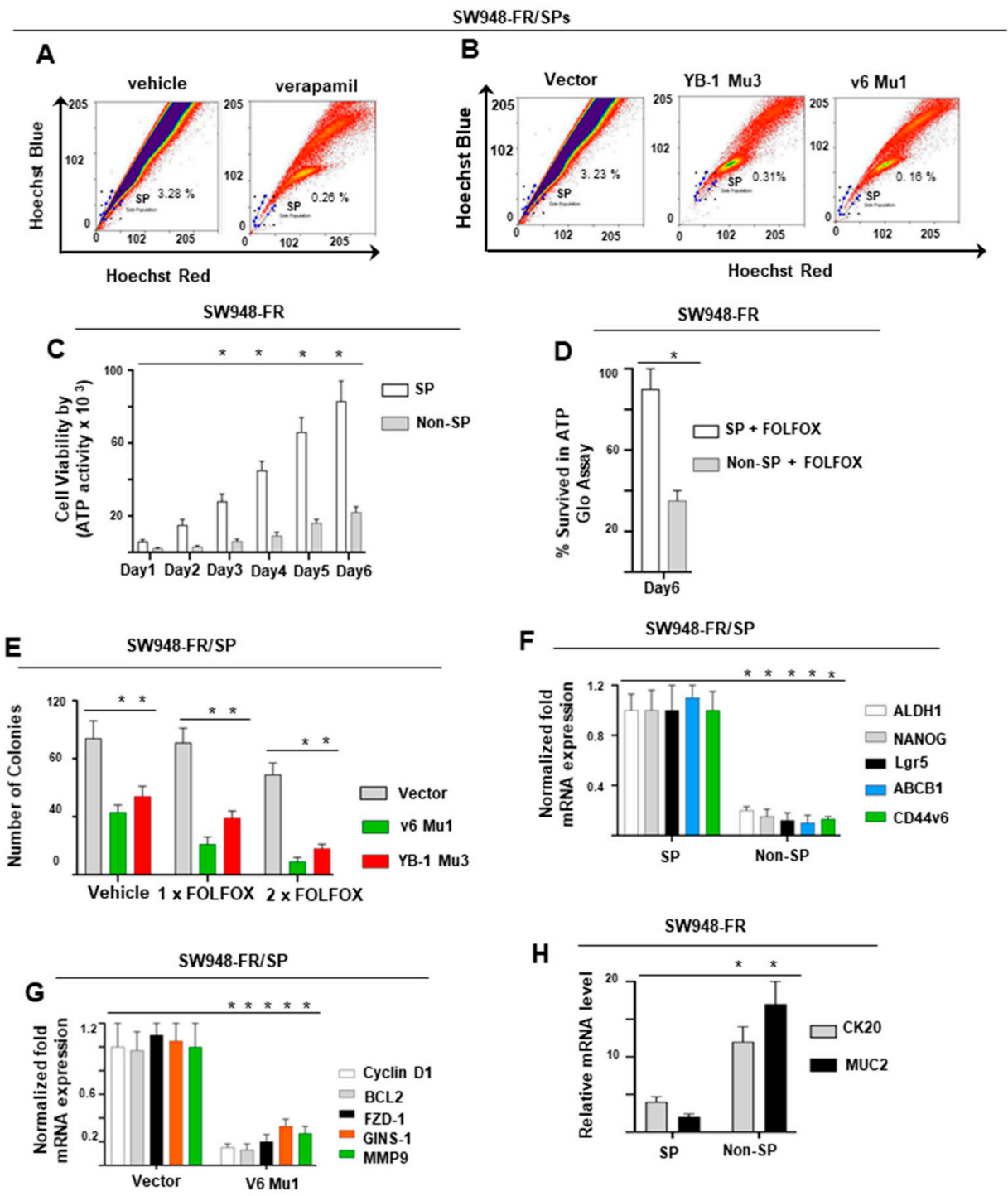

Figure 5. CD44v6-YB-1 defines CIC-like SP cells. (A) SW948-FR cells labeled with Hoechst 33342 showed 3.3\% of SP cells in the SP gated region. Following treatment with verapamil, the SP cells were reduced to 0.26\%. (B) v6 Mu1 and YB-1 Mu3 regulate the side population. The SP cells were $<10 \%$ of vector cells in the v6 Mu1 cells, and the YB-1-Mu3 SW948-FR cells. (C) Cell proliferation rates were measured by ATP GLO assay for SP and non-SP cells. SP cells underwent rapid proliferation compared with non-SP cells. (D) SP cells exhibited high resistance to $1 \times$ FOLFOX whereas the non-SP cells were sensitive to $1 \times$ FOLFOX. (E) CD44v6 and YB-1 knockdown in SW948-FR cells decreased the drug resistance. Control, v6 Mu1, and YB-1 Mu3 SW948-FR cells were treated with various doses of FOLFOX for 10 days in 3\% FBS DMEM. Cell viability was assessed using the clonogenic assay. The clonogenicity of CD44v6-Mu1 cells was significantly decreased compared with YB-1-Mu3 cells. (F) Expressions of core stemness genes in SW948-FR/SP and non-SP cells by QPCR are shown. (G) Expressions of anti-apoptosis/stemness-related genes in vector and v6 Mu1 transfected SW948-FR/SP cells are shown. (H) Expressions of CRC differentiation genes in SW948-FR/SP and non-SP cells are shown. Each bar represents the means of three determinations $\pm \mathrm{SD} .{ }^{*} p<0.05$ among the indicated groups compared to respective control group. FACs data are representative of three experiments. 




D

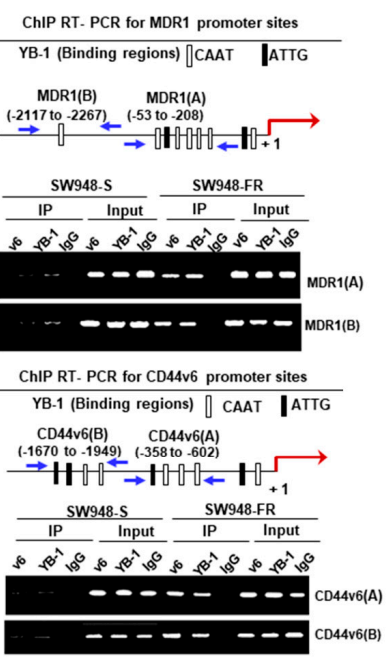

J ChIP qPCR for CD44v6 promoter sites

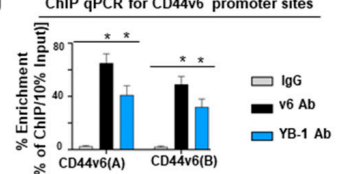

B


Figure 6. Nuclear YB-1 binds with CD44v6 and modulates CD44v6 and MDR1 transcription by binding to CD44v6 and MDR1 promoters. (A) Nuclear extracts were isolated from SW948-S and SW948-FR cells first transfected with vector, or v6 Mu1, and then treated with or without $1 \times$ FOLFOX for $8 \mathrm{~h}$. Nuclear extracts were immunoprecipitated by YB- 1 antibody followed by Western blotting of the indicated proteins. (B) The scheme shows the MDR1 promoter constructs with YB-1 binding sites (mdr1(1) and mdr1(2)). (C) MDR1 Luciferase activities are shown for SW948-FR/CICs overexpressing CD44v6 Mu1, or YB-1 Mu3, or vector (Control) for $24 \mathrm{~h}$. (D,F) MDR1 is transcriptionally regulated by YB-1 in SW948-FR/CICs. (D) The sketch map shows the predicted YB-1 binding sites (CAAT or ATTG) within the MDR1 promoter (MDR1(A) and MDR1(B)). PCR primers designated for MDR1(A) and MDR1(B) were used for amplification of the potential YB-1 binding sites of the MDR1 gene by ChIP semiquantitative PCR assays using anti-CD44v6, anti-YB-1, or an irrelevant IgG antibody (control). Total genomic DNA was used as input for the ChIP PCR. (E) ChIP QPCRs representing the PCR products in CD44v6, YB-1, or IgG immunoprecipitated DNA versus 10\% input DNA in SW948-FR/CICs using primers for MDR1(A) and MDR1(B) sites are shown. (F) ChIP QPCRs representing the PCR products in CD44v6, YB-1, or IgG in SW948-FR/CICs overexpressing CD44v6 Mu1, or YB-1 Mu3, or vector for $24 \mathrm{~h}$ are shown. (G) The sketch map of predicted YB-1 binding sites (CD44v6 [1] and CD44v6 [2]) within the CD44v6 promoter is shown. (H) CD44v6 luciferase assays are shown for SW948-FR/CICs overexpressing v6 Mu1, or YB-1 Mu3, or vector for $24 \mathrm{~h}$. (I) Semiquantitative PCR products using ChIP QPCR primers are shown for designated YB-1 binding sites as CD44v6(A) and CD44v6(B). (J) A representative ChIP QPCR representing the PCR product in immunoprecipitated CD44v6 is shown. (K) ChIP QPCR using PCR primers for designated CD44v6(A) sites were used for amplification of the YB-1 binding sites of the CD44v6 gene in ChIP assays in untreated CICs, or CICs overexpressing CD44v6 Mu1, or YB-1 Mu3, or vector (Control) for $24 \mathrm{~h}$. Values represent means \pm SD; $n=3-5 ;{ }^{*} p<0.05$, compared to whole cell lysate and nuclear fractions isolated from sensitive cells, sensitive cell groups, vehicle control, IgG control, vector control, and appropriate control groups. Western blot and semiquantitative PCR data are representative of three experiments. 


\subsection{Role of CD44v6-YB-1 in the Tumorigenesis of CICs of Resistant Cells In Vivo}

To evaluate the impact of CD44v6-YB-1 on the tumorigenesis of CICs in vivo, v6 Mu1 and YB-1 Mu3 knockouts in SW948-FR-CICs and WT CICs, were injected into nude mice. Our results indicated that tumor growth in mice injected with v6 Mu1 CICs and YB-1 Mu3 CICs transplanted tumors were significantly suppressed compared with those in control mice (Figure 7A). The tumors in mice injected with v6 Mu1 CICs were smaller and weighed less than YB-1 Mu3 CICs (Figure 7B). In addition, Western blot data revealed that the CD44v6 and YB-1 proteins were detected lesser in tumors in mice injected with v6 Mu1 CICs or with YB-1 Mu3 CICs (Figure 7C). The residual expression of YB-1, and ABCB1 (MDR1) protein in v6 Mu1 CIC injected tumors (Figure 7C) suggest that in addition to CD44v6-YB-1, other signaling cascades may also mediate the potential of FOLFOX to stimulate YB-1 expression/activity.
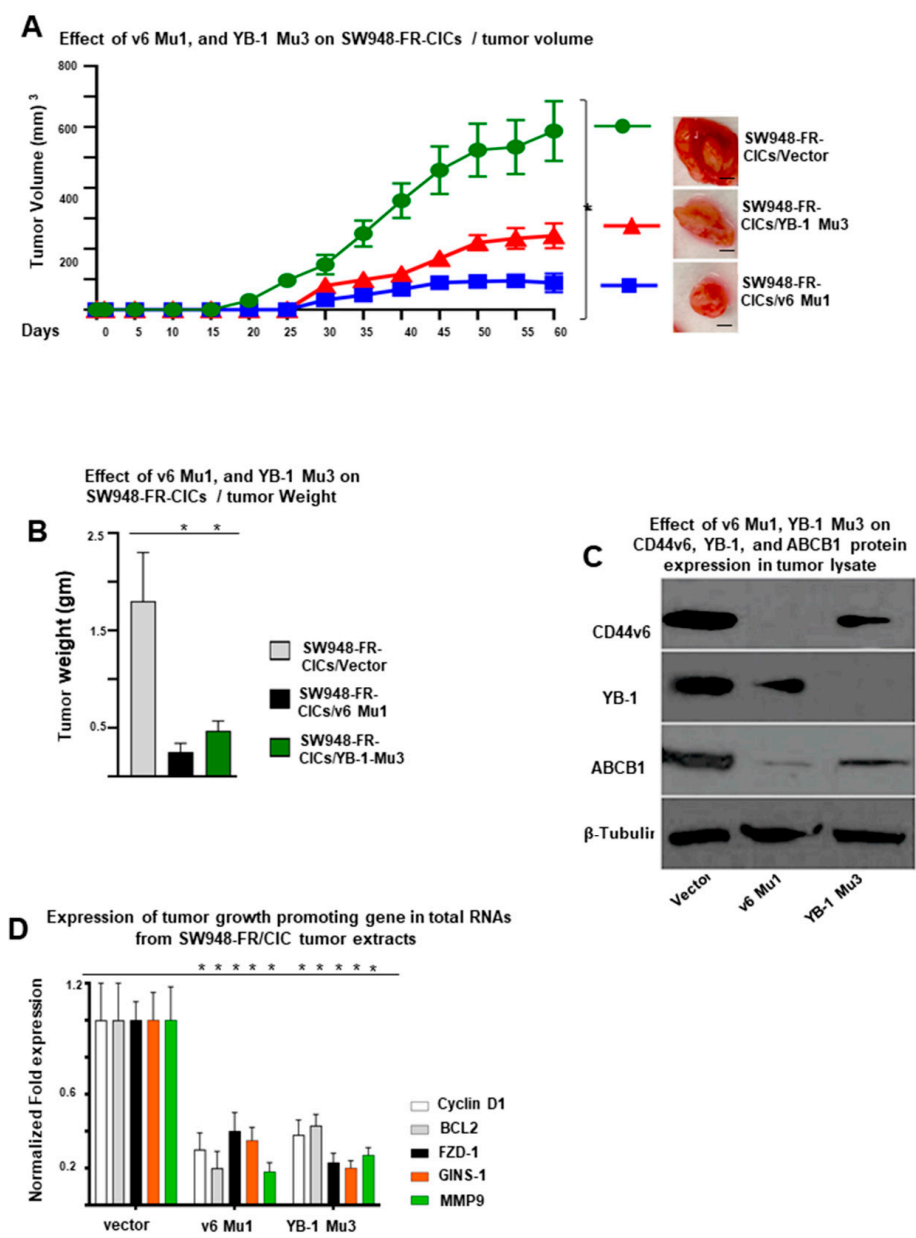

Figure 7. Role of CD44v6 in the SQ tumorigenesis of SW948-FR/CICs in vivo. (A,B) Effects of CD44v6, or YB-1, or a combination of CD44v6 + YB-1 knockout on tumor growth in nude mice are shown. CD44v6 Mu1, YB-1 Mu3, or v6 Mu1 + YB-1 Mu3 knockout FOLFOX resistant CRC CICs and wide-type CICs were injected into nude mice. The tumor volumes in mice were measured every five days (A). Sixty days later, the mice were sacrificed. A solid tumor was collected from each mouse. (B) The impacts of v6 Mu1, YB-1 Mu3 knockout FOLFOX resistant CRC CICs on tumor weights are shown. (C) The CD44v6, MDR1, and YB-1 protein levels in tumors of mice injected with v6 Mu1, YB-1 Mu3 knockout FOLFOX resistant CRC CICs or WT CICs are shown. $\beta$-Tubulin was used as an internal control. (D) Expressions of proliferation/antiapoptosis/invasion/stemness related genes (by QPCR) in these solid tumors are shown. Data are presented as mean $\pm \mathrm{SD}(n=7) ;{ }^{*} p<0.05$. ANOVA followed by Bonferroni's post-hoc test was used to assess the significance. Western blot data are representative of three experiments. QPCR data are presented as mean $\pm \operatorname{SD}(n=4){ }^{*} p<0.05$. Scale bar, $50 \mu \mathrm{m}$. 
These results showed that CD44v6 knockout v6 Mu1 SW948-FR cells inhibited the tumorigenesis of CICs in vivo. As CD44v6 defined CICs autonomous resistance (Figure 4A-D) and has been proven to participate in the transcriptional regulation and activation of stemness factors in resistant SW948-FR CICs and SP cells (Figures 4E and 5D,F), we investigated the effects of CD44v6 knockout on the expression of CD44v6/YB-1 target genes in vivo. The QPCR analysis of the xenograft tumor RNAs showed that the stemness-associated genes were considerably decreased in YB-1 Mu3 knockout tumors compared with those in WT control tumors (Figure 7D). These findings further suggest that CD44v6 promoted the expression of stemness-associated genes including MDR1 to enhance the tumorigenesis of $\mathrm{CICs}$ in vivo and that this function of CD44v6 requires a positive feedback loop coupling CD44 alternative splicing and it's downstream target YB-1 activation.

\section{Discussion}

Classically, CSCs/CICs are most often defined as being multipotent, long-lived, slow cycling/quiescent, self-renewable, and asymmetrically dividing cells within a tumor that have tumorigenic potential when transplanted into immune-deficient mice [10,145-147]. Thus, CICs are primarily involved in maintenance of tissue homeostasis and recovery from injury. CICs can be separated from other cancer cells based on their distinctive cell surface markers depending on the cancer of origin [148]. Due to CIC's self-renewal and multilineage differentiation characteristics, tumors are composed of a biological hierarchy of cell types that is dictated by CICs [149]. As a result of its self-renewing capabilities, CICs can be serially transplanted through multiple generations to relapse the tumor with strong drug-resistance and metastatic traits [38]. While surgical removal and adjuvant therapy can cure well-confined primary tumors, resistant tumors that are metastatic are largely incurable because of the resistance of disseminated tumor cells to existing therapeutic agents of standard care [150-152]. Thus, the identification of the molecular mechanisms involved in FOLFOX resistance provides strong impetus to investigate therapeutically tenable cellular/molecular pathways for reversal of resistance.

With regard to cancer mimicking development and wound response outcomes, CICs function in two settings. First, stem cells were initially described in acute myeloid leukemia [153], but soon were also found in solid tumors including colorectal cancers [154]. Single hematopoietic stem cells repopulate to the bone marrow niche via systemic blood circulation, and the niche then directs instructive signals to sustain proliferative potential of stem cells. Second, organ regeneration by single hematopoietic stem cells is less evident in solid tumor tissue. Recent work in CRC has shown that the inner surface epithelium of the colon is folded into crypts where stem cells display a cooperative relationship with supportive CD24+ (or cKit+) accessory cells similar to small intestinal Paneth cells. Paneth cells (CIC niche cells) potentially proliferate significantly relative to single stem cells, and they provide maintenance signals and restrain uncontrolled growth. When a stem cell exits its niche, it undergoes lineage specification and differentiation, providing an essential role for the stromal-environment to influence normal cellular hierarchies [147].

Colorectal CICs with epithelial characteristics, i.e., EpCAM (+) CD44v6 (+) [27,154], share the major intestinal stem cell features, including self-renewal, telomerase activity, organspecific differentiation potential, unusual activation of proliferating signaling including CD44v6 and WNT/ $\beta$-catenin, elevated tumorigenic potential, and drug-resistance [155-157]. In CRC, tumor cells are closely associated with cancer associated fibroblasts, which secrete different stromal factors, including hepatocyte growth factor, WNT, TGF $\beta$, periostin, prostaglandin E2 (PGE2), bone morphogenetic protein (BMP), and interleukins produced by the tumor microenvironment, which in turn promotes tumor stemness and CIC clonogenicity $[13,72,158-160]$. These factors in turn induce the expression of different transcription factors (TFs), including TWIST1 and Snail. These TFs repress E-cadherin expression, and trigger EMT, which enables cancer cells to disseminate and acquire the ability to self-renew and resist apoptosis [72,134]. For self-renewal and drug resistance function CICs express a distinct set of markers (ABC transporters, CD133, EpCAM, Lgr-5, or ALDH1) [84] 
as well as their associated TFs, and stemness genes including BIM-1, NANOG [134,135], TWIST, OCT-4 [161-163], SOX2 [161,164], and FZD1 [117]. In addition to being CIC markers, these molecules are biologically functional and can be expressed in tumor cells by continuous activation of transcriptional networks that constitutively express high levels of stemness-associated TFs $[79,134,135,161,164,165]$.

In this study, we demonstrated that CRC-CICs express CD44v6, which is a functional marker involved in autonomous resistance of CICs to FOLFOX therapy and was validated by the major inverse correlation between tumor survival and CD44v6 expression. Additionally, we showed that the YB-1 oncogene is widely expressed in CD44v6+ CICs, thus enabling these CICs to be highly resistant to FOLFOX therapy. Further we show for the first time that CD44v6 induces YB-1 through CD44v6 regulated PGE2-mTOR signaling in response to FOLFOX, and that CD44v6-YB-1 promotes tumor sphere, soft agar colony formation, and drug-resistance in CRC-CICs. In addition, we found that FOLFOX resistant cells contained more SP cells compared to the FOLFOX sensitive cells. Furthermore, SP cells highly expressed stemness-related genes and resistance to FOLFOX. Importantly, we found that SP cells in CRC had significantly increased activation of CD44v6 and YB-1 expressions compared to non-SP cells. Knocking down CD44v6 in SP cells significantly decreased stemness related genes and increased differentiation markers. Further, SP cells in FOLFOX resistant CRC cells were highly tumorigenic in vivo compared to non-SP cells. Therefore, these findings indicate that $\mathrm{SP}$ cells are likely to be a major driving force of $\mathrm{CRC}$ resistance to FOLFOX, indicating that the CD44v6-YB-1 signaling pathway may be an important target for eliminating CICs in CRC.

The CIC subpopulation can differentiate into non-CIC tumor cells and promote phenotypic and functional heterogeneity within the tumor. In 2006, Yamanaka lab showed that terminally differentiated fibroblasts can be reprogrammed to induced pluripotent stem cells (iPSC) using four transcription factors OCT4, SOX2, KLF4, and c-Myc by initiating several synergistic processes $[130,166]$. Thus, any somatic cell can be reprogrammed into iPSC cells by coexpression of stemness-related core transcription factors that are specific for tumor cell type, and these TFs can act in partnership to regulate the expression of discrete genes specific for maintaining stem cell pluripotency and self-renewal [167-170]. Such factors specific to each tumor type maintain the dynamic balance between CICs and differentiated cells in a proper equilibrium. Dedifferentiation can alter this equilibrium resulting in metastasis/aggressiveness since CICs are resistant to chemotherapy and radiation. In this study, our results showed that CD44v6 knockout induced differentiated CICs, leading to the decrease of sphere-forming ability and downregulation of stemness genes related to CICs. However, CD44v6 rescue alone in the v6 Mu1 SW948-CICs did not reprogram the differentiated cells into CICs, which was in agreement with the previous studies $[79,130]$. Our results revealed that v6 Mu1 knockout CICs significantly promoted the expression of differentiation genes (CK20 and MUC2). We also revealed that the simultaneous expressions of c-Myc, TWIST1, Oct 4, and SOX2 (CTOS)), and a v6 rescue plasmid reverted v6 Mu1 CICs into CICs. Therefore, our study showed that differentiated cells can be reprogrammed into CICs via combined expression of CTOS TFs and CD44v6. This indicates that CD44v6 induced YB-1 was required for the reversion of differentiated cancer cells into CICs. Overall, we can conclude that after FOLFOX stimulation, internalized CD44v6 complexes with YB-1, and the combined signaling complex reaches the nucleus, where CD44v6 regulated YB-1 stimulates promoters for the MDR1 and CD44v6 genes, which sustains FOLFOX resistance and tumor formation through CD44v6 overexpressing CICs. This provides evidence that CD44v6 is a biomarker and a likely therapeutic target. In addition, CD44v6-YB-1 interaction could promote CIC proliferation, maintain CIC stemness, and suppress CIC apoptosis by enhancing the expression of TFs (NFkB, E2F1, STAT3, and RUNX2) for proliferation/antiapoptosis/invasion/stemness related promoters (Cyclin D1, FZD1, GINS1, BCL2, and MMP9). Therefore, CD44v6-YB-1 signaling has a vital role in the activation and reversion of the differentiated cancer cells into CICs. 


\section{Material and Methods}

\subsection{Materials}

Dulbecco's Modified Eagle's Medium (DMEM), Eagle's Minimum Essential Medium (EMEM), McCoy's 5A Medium, F-12K Medium, Leibovitz's L-15 Medium, L-Glutamine, Sodium pyruvate, Penicillin $(100 \mu / \mathrm{mL})$, and Streptomycin $(100 \mu \mathrm{g} / \mathrm{mL})$, sodium pyruvate, $0.05 \%$ EDTA solution (Versene), Phosphate buffered saline (PBS, Calcium and Magnesium free), and $0.05 \%$ Trypsin were from Corning Inc. (Upstate, NY, USA). Fetal Bovine Serum (FBS) was from Atlanta Biologicals (Minneapolis, MN, USA). Amphotericin B was from Hyclone (Logan, UT, USA). Nonidet P-40, EGTA, sodium orthovanadate, glycerol, phenylmethylsulphonyl fluoride, leupeptin, pepstatin A, aprotinin, and HEPES, Insulin and B-27, Hoechst 33342 were from Sigma (St. Louis, MO, USA). Collagenase was from Worthington Biochemical (Lakewood, NJ, USA). Fc blocking reagent was from Millenia Biotech (Gießen, Germany). bFGF, Blocking antibody for CD44v6 (2F10), IL17A and isotype control were from R\&D Systems (Minneapolis, MN, USA). TrypLE, Lipofectamine 2000 was from Invitrogen (Carlsbad, CA, USA). The $50 \mu \mathrm{m}$ nylon mesh was from BD Biosciences Thermo Fisher (Waltham, MA, USA). Lipofectamine 2000 was from Invitrogen (Carlsbad, CA, USA). T7E1 was from New England Biolabs (Beverly, MA USA). The antibodies against CD44v6, YB-1, E-Cadherin, EpCAM, ALDH1, NANOG, Lgr5, EpCAM, CD133, $\beta$-catenin, Anti-Active- $\beta$-catenin (anti-ABC) antibody, clone 8E7, TCF4, MDR1, Cyclin D1, BCL2, FZD1, GINS-1, MMP9, $\beta$-tubulin, horseradish peroxidase-linked antirabbit and anti-mouse antibodies, and Luminol reagent were purchased from commercial sources (R\&D (Minneapolis, MN, USA), Santa Cruz Biotechnology Inc. (Dallas, TX, USA), Abcam (Cambridge, MA, USA), Ebioscience Thermo Fisher, Thermo Fisher (Waltham, MA, USA), and Cell Signaling Technology (Danvers, MA, USA). Blocking antibody for CD44v6 (2F10), IL17A and isotype control were from R\&D Systems. Blocking antibody for periostin (OC-20) was from Adipogen Life sciences (San Diego, CA, USA). Blocking antibody for WNT3A (1H12L14) was from Thermo Fisher (Waltham, MA, USA).

\subsection{Cell Lines}

Human colorectal adenocarcinoma cell lines: (1) HT29 (HTB-38) purchased from ATCC (Manassas, VA, USA)was maintained in McCoy's 5A medium $+2 \mathrm{mM}$ Glutamine $+10 \%$ Fetal Bovine Serum (FBS); (2) pre-neoplastic Apc 10.1 cells isolated from Apc min/+ mice were cultured in Dulbecco's modified Eagle medium supplemented with 20\% FBS and harvested by a 15-30 min treatment with trypsin-EDTA solution [48,171]; (3) Colo 205 and Colo 320DM, SW707, and HCT15 cells purchased from ATCC and Cellosaurus were cultured in ATCC-RPMI $1640+2 \mathrm{mM}$ Glutamine + 10\% FBS; (4) SW620 and SW948 cells purchased from ATCC were cultured in Leibovitz's L-15 Medium $+2 \mathrm{mM}$ Glutamine $+10 \%$ FBS. The cell lines were maintained in medium mentioned next to the cell line in humidified atmosphere in the presence of $10 \%$ FBS, penicillin $(100 \mu \mathrm{g} / \mathrm{mL})$, and streptomycin $(100 \mu \mathrm{g} / \mathrm{mL}), 5 \% \mathrm{CO}_{2}$ at $37^{\circ} \mathrm{C}$.

\subsection{Generation of FOFOX Resistant (FR) Cells}

To determine the mechanisms of FOLFOX resistance, we selected three cell lines (HT29, and SW948) out of seven cell lines (Supplemental Figure S1A), which have low basal levels of CD44v6 gene expression. Using these cell lines, we determined their $\mathrm{IC}_{50}$ values for 5-Flourouracil (5-FU) and their $\mathrm{IC}_{50}$ values for Oxaliplatin (OXA) (Figure S1B-D) because these molecules are the components of FOLFOX. To determine these $\mathrm{IC}_{50}$ values, cells were separately pretreated with various concentrations of 5-FU, or OXA, or vehicle. After a 24 -h incubation at $37^{\circ} \mathrm{C}$, growth assays were analyzed as described above. The $50 \%$ inhibitory concentration $\left(\mathrm{IC}_{50}\right)$ was identified as a concentration of drug required to achieve a $50 \%$ growth inhibition relative to untreated controls. The average $\mathrm{IC}_{50}$ values for HT29, and SW948 cells for 5-FU is $50 \mu \mathrm{M}$ and for OXA is $10 \mu \mathrm{M}$. FOLFOX resistance cells were generated by incubating the sensitive parental (HT29-S, and SW948-S) cells with increasing concentrations from $1 \times$ FOLFOX (50 $\mu \mathrm{M}$ 5-FU $+10 \mu \mathrm{M}$ OXA $+1 \mu \mathrm{M}$ leucovorin) to 
$5 \times$ FOLFOX over 3 days. The surviving FOLFOX resistant (FR) cells were cultured in normal medium for 5 days. This exposure and withdrawal cycle were repeated five times for each dose of FOLFOX. The resistances of these FR clones were compared to sensitive pairs by determining the number of colonies in soft agar growth with $1 \times$ FOLFOX $-5 \times$ FOLFOX therapy.

\subsection{Isolation of CICS}

Our FOLFOX resistant (FR) clones and the corresponding sensitive pairs were maintained through subcutaneous xenografts in the flanks of immunocompromised SCID mice. Fresh normal colonic tissue and colorectal tumors were rinsed in DMEM (Life Technologies) supplemented with 200 units $/ \mathrm{mL}$ of penicillin, $200 \mu \mathrm{g} / \mathrm{mL}$ of streptomycin, and 4 units $/ \mathrm{mL}$ of amphotericin B and minced, followed by incubation with 300 units $/ \mathrm{mL}$ of collagenase at $37^{\circ} \mathrm{C}$ for $3 \mathrm{~h}$. A single cell suspension was obtained by filtration through a $40 \mu \mathrm{m}$ filter. After discarding lymphocytes by gradient centrifugation, the cells were washed twice in fluorescence-activated cell sorting (FACS) buffer (Phosphate-buffered saline (PBS) $+2 \%$ $\mathrm{BSA}+1 \mathrm{mM}$ EDTA $+0.1 \%$ sodium azide), incubated with Fc blocking reagent and stained with directly with conjugated antibodies by incubating on ice for $20 \mathrm{~min}$. They were then sorted in a Mo Flo cell sorter for EpCAM+CD44v6+ALDH1+CD133+ (CD44v6 high CICs) by using appropriate fluorescent conjugated antibodies. They were further confirmed by tumor sphere formation abilities and in vivo tumorigenicities by testing for tumor sphere formation at $37{ }^{\circ} \mathrm{C}$ in an atmosphere of $5 \% \mathrm{CO}_{2}$. CICs were cultured in serum-free medium with basic fibroblast growth factor (bFGF, $10 \mathrm{ng} / \mathrm{mL}$ ) and epidermal growth factor (EGF, $10 \mathrm{ng} / \mathrm{mL}), 5 \mu \mathrm{g} / \mathrm{mL}$ of insulin, and $2 \%$ of B- 27 at $37^{\circ} \mathrm{C}$ in a humidified atmosphere with $5 \% \mathrm{CO}_{2}$. For cell counting, before each experiment, a single-cell suspension was achieved using TrypLE (Invitrogen) dissociation.

\subsection{Labeling of Cells with Hoechst 33342}

Approximately $10^{6}$ cells/mL from WT, v6 Mu1, YB-1, Mu3 SW948-FR cells in 10\% DMEM were labeled with Hoechst 33342 stock bis-benzamide $(5 \mu \mathrm{L} / \mathrm{mL})$ either with dye alone or in combination with drug treatment (verapamil, $0.8 \mu \mathrm{L} / \mathrm{mL}$ ). After $90 \mathrm{~min}$ incubation in a water bath at $37^{\circ} \mathrm{C}$, cells were subjected to centrifugation at $2500 \times g$ for $10 \mathrm{~min}$ at $4{ }^{\circ} \mathrm{C}$ and resuspended in $500 \mu \mathrm{L}$ of Hank's balanced salt solution containing $10 \mathrm{mM}$ HEPES (4-[2-hydroxyethyl]-1-piperazineethanesulfonic acid). Finally, cells were counterstained with propidium iodide $\left(2 \mu \mathrm{g} / \mathrm{mL}\right.$ sample) at $4{ }^{\circ} \mathrm{C}$ to exclude dead cells. Cells were filtered through a $50 \mu \mathrm{m}$ nylon mesh to remove cell clumps into labeled fluorescenceactivated cell sorting (FACS) tubes. The SP cells and main population (non-SP) cells were sorted using a flow cytometer. The Hoechst 33342 dye was excited at $355 \mathrm{~nm}$, and its dual-wavelength fluorescence was analyzed (blue, $450 \mathrm{~nm}$; red, $675 \mathrm{~nm}$ ).

\subsection{Establishment of CD44v6 Knockout Mutant and YB-1 Knockout Mutant of CICs by the CRISPR/Cas9 System}

A guide RNA for CD44v6 and a guide RNA for YB-1 were designed using the ZiFit Web application (http:/ / zifit.partners.org/) to aim at exon 6 of CD44, and at exon 1 of $Y B-1$. The gene-specific guide RNA sequence for CD44v6 was 5'-GGGGTAGGGTCTGCTTCTGT CAGGG-3'; and for YB-1 was 5'-CGGCGGGGGGGGCGGGG-3, which were cloned separately into the px458 vector (Addgene, Cambridge, MA, USA). Plasmid construction, transfection into sensitive and FR-resistant CRC CICs using Lipofectamine 2000 from Invitrogen (Carlsbad, CA, USA), and isolation of clonal CICs were conducted as described previously [172]. To evaluate the gene editing activity of gRNA, the genomic DNAs of gRNA-transfected CICs were extracted, and the CD44v6 and YB-1 genes were amplified using sequence-specific primers followed by digestion with T7 endonuclease 1 (T7E1) from New England Biolabs (Ipswich, MA, USA) at $37^{\circ} \mathrm{C}$ for $30 \mathrm{~min}$. The digested products were analyzed with agarose gel electrophoresis. Subsequently, the cells were cultured in the serum-free medium with basic fibroblast growth factor (bFGF, $10 \mathrm{ng} / \mathrm{mL} ; \mathrm{R} \& \mathrm{D}$ Systems) and epidermal growth factor (EGF, $10 \mathrm{ng} / \mathrm{mL} ; \mathrm{R} \& D$ Systems), $5 \mu \mathrm{g} / \mathrm{mL}$ of insulin 
(Beyotime, Shanghai, China), and $2 \%$ of B-27 (Sigma, St. Louis, MO, USA) at $37^{\circ} \mathrm{C}$ in a humidified atmosphere with $5 \% \mathrm{CO}_{2}$ for 2 days. Single colonies were selected by antibiotic selection, passaged, and genotyped. The knockout mutants were confirmed by DNA sequencing and Western blot with CD44v6 and YB-1-specific antibodies.

\subsection{RNA Silencing}

For determining shRNA sequences used in this study, (1) coding nucleotide sequences of the genes were obtained from the NCBI, National Institutes of Health, website (www. ncbi.nlm.nih.gov); (2) hairpin shRNAs were designed to target a transcript sequence using the Broad Institute GPP Web Portal (http:/ / portals.broadinstitute.org/gpp/public/); (3) sequences for cloning in pSico/pSicoR vectors were designed following the MIT Jackson Lab website (http://web.mit.edu/jacks-lab/protocols). The resulting pSicoR-CD44v6 shRNA1 (CD44v6 sh1), pSicoR-CD44v6 shRNA2 (CD44v6 sh2) transfectants constitutively silence respective CD44v6 genes in the cells. The pSicoR-Non targeted shRNA (NT sh) transfectants were used as control to the above shRNA transfectants (see Table 1 for shRNA sequences used in this study).

Table 1. shRNA sequence in pSico and pSicoR vectors (https://jacks-lab.mit.edu/protocols).

\begin{tabular}{|c|c|c|}
\hline \multirow{2}{*}{ Genes } & \multicolumn{2}{|c|}{ Primers } \\
\hline & Sense Sequence $\left(5^{\prime}-3^{\prime}\right)$ & Antisense Sequence $\left(5^{\prime}-3^{\prime}\right)$ \\
\hline \multirow{2}{*}{ CD44v6 shRNA1 } & TCCTCCCAGTATGACACATATTTTCAAGAGA & TCGAGAAAAAACCTCCCAGTATGACACATATT- \\
\hline & -AATATGTGTCATACTGGGAGGTTTTTTC & TCTCTTGAA-AATATGTGTCATACTGGGAGGA \\
\hline \multirow{2}{*}{ CD44 shRNA2 } & TGGACCAATTACCATAACTATTTTCAAGAGA & TCGAGAAAAAAGGACCAATTACCATAACTATT \\
\hline & AATAGTTATGGTAATTGGTCCTTTTTTC & TCTCTTGAA-AATAGTTATGGTAATTGGTCCA \\
\hline
\end{tabular}

To rescue the shRNA knocked out gene, cells were transfected with the gene replacement vector containing the modified target gene (Knock-In (KI; shRNA-immune cDNA)) that no longer contains target sites for the shRNAs but still encodes a functional protein. This can often be achieved by utilizing one or more silent third-codon point mutations within the targeted region. This construct restores full function and rescues any loss-offunction phenotype as used in our previous study $[57,58]$.

\subsection{CR1SPR/Cas9 Knockout Mutant Gene Rescue Plasmids}

When a gene is knocked out in cells, it is important to know if rescue of the original gene would reverse the downstream changes in order to authenticate the gene function. In both scenarios, reintroducing a mutant(s) and/or rescuing of a wildtype gene would fail because Cas9-gRNA by nature disrupts introduced genes. To overcome both hurdles, we used modified cDNAs for gene rescue. In case of CR1SPR/Cas9 gene knockout, because Cas9 cleaves where gRNA binds, one or a few nucleotides in the gRNAS binding site of the CD44v6 and YB-1 were modified by three nucleotides, while the amino acid sequences remained unchanged as described previously in generating shRNA resistant constructs and gRNA rescue constructs $[57,58,173]$. Total cell lysates were examined by Western blot analysis for the indicated proteins and $\beta$-tubulin or $\beta$-actin were used as internal standards. In some cases, total mRNAs were analyzed for the indicated mRNAs by QPCR.

\subsection{Cell Growth Survival or Apoptosis Assays}

Five thousand cells were plated in triplicate into 96-well plates containing appropriate growth media and incubated overnight. After $16 \mathrm{~h}$ of growth, cultures were incubated in media containing no serum for $16 \mathrm{~h}$ at $37^{\circ} \mathrm{C}$ in $5 \% \mathrm{CO}_{2}, 95 \%$ air. Vehicle or chemotherapy drug was added to the plate. In each experiment, a total of five plates (six wells/treatment) were used. Experiments were repeated three times. The growth of these cells was determined by measuring increases in readings of ATP levels for viability (Cell Titer-Glo, Promega). The luminescent signal is proportional to cell viability and is measured using 
a luminometer (PerkinElmer). The Caspase-Glo ${ }^{\circledR} 3 / 7$ assay depends on the formation of free amino luciferin after adding caspase-3/7 DEVD-amino luciferin substrate to cell lysates and measuring amino luciferin by the luciferase present in the substrate reagent. The luminescent signal is proportional to caspase $3 / 7$ activity and measured using a luminometer.

\subsection{Tumor Sphere Formation}

An optimized serum substitute $(1 \times$ B27 supplement) (from Creative Bio array) was freshly added to tumor formation medium $(500 \mathrm{~mL}$ Dulbecco's Modified Eagle Medium/F12 containing, $20 \mathrm{ng} / \mathrm{mL}$ epidermal growth factor; $10 \mathrm{ng} / \mathrm{mL}$ basic fibroblast growth factor; $5 \mu \mathrm{g} / \mathrm{mL}$ insulin; $0.4 \%$ bovine serum albumin). After harvesting the cells, 200 live cells in $200 \mu \mathrm{L}$ of tumor sphere medium were suspended in ice. This suspension was kept on ice and mixed well for plating. PBS was added to the first and last columns (columns 1 and 12) of the 96-well plate to help minimize medium evaporation. This leaves 10 wells available for each row. Then, $200 \mu \mathrm{L}$ aliquots of the cells were suspended in tumor sphere medium into each well (200 cells per well). For each treatment, cells were seeded into the wells of two rows for a total of 20 wells. The upper and lower edges of the 96-well plate were sealed with laboratory tape to avoid evaporation of medium, and cells were placed in an incubator at $37^{\circ} \mathrm{C}$ and cultured in $5 \% \mathrm{CO}_{2}$ for $10-14$ days. After stipulated time of incubation, tumor sphere numbers were counted under a phase-contrast microscope using the $40 \times$ magnification lens. Data are presented as a percentage of wells containing tumor spheres compared to the total number of wells.

\subsection{Cell Lysis and Immunoblotting}

Cells were cultured until they were $75 \%$ confluent. They were washed twice at $4{ }^{\circ} \mathrm{C}$ with phosphate buffered saline (PBS), harvested with $0.05 \%$ Versene, and then washed in cold PBS again. The cells were pelleted by centrifugation at $5000 \times \mathrm{g}$ for $2 \mathrm{~min}$ at $4{ }^{\circ} \mathrm{C}$. The pellets were treated with the lysis buffer containing $1 \%$ Nonidet P-40, $0.5 \mathrm{mM}$ EGTA, $5 \mathrm{mM}$ sodium orthovanadate, $10 \%(\mathrm{v} / \mathrm{v})$ glycerol, $100 \mu \mathrm{g} / \mathrm{mL}$ phenylmethylsulphonyl fluoride, $1 \mu \mathrm{g} / \mathrm{mL}$ leupeptin, $1 \mu \mathrm{g} / \mathrm{mL}$ pepstatin $\mathrm{A}, 1 \mu \mathrm{g} / \mathrm{mL}$ aprotinin, and $50 \mathrm{mM}$ HEPES, $\mathrm{pH} 7.5$. The lysates were clarified by centrifugation at $12,000 \times \mathrm{g}$ for $10 \mathrm{~min}$ at $4{ }^{\circ} \mathrm{C}$ and then stored at $-80{ }^{\circ} \mathrm{C}$ as described previously [57,58,174-176]. Cell lysates (normalized for protein concentration) were analyzed by immunoblotting as described previously $[57,58,174-176]$. The proteins on the blots were analyzed with antibodies from commercial sources for specific antibodies for each experiment using appropriate primary antibodies ( $\beta$-tubulin and $\beta$-actin were used as internal standards). Proteins probed with primary antibodies were detected by treatment with horseradish peroxidase-linked anti-rabbit or anti-mouse antibodies as secondary antibodies followed by treatment with luminol reagent (Santa Cruz Biotechnology). Each protein was analyzed in samples from at least three independent experiments from each set of tumor cells and from CICs.

\subsection{Coimmunoprecipitation and Pulldown}

The roles of CD44v6 knockout on colocalization of CD44v6, YB-1, and MDR1 in nuclear extracts were determined by pull down with YB-1 antibody followed by Western blotting analysis. After immunoprecipitation, cells were washed with ice cold PBS and lysed in lysis buffer as described above for $30 \mathrm{~min}$. The 10\% cell lysates were kept without antibody immunoprecipitation (IP) for input control, and were analyzed by SDS PAGE on the same gel with the Co-IP samples. Immunoprecipitation was done on cleared lysates $\left(12,000 \mathrm{rpm}\right.$ for $15 \mathrm{~min}$ at $\left.4{ }^{\circ} \mathrm{C}\right)$ with indicated antibodies and protein $\mathrm{G}$ agarose beads (Merck) at $4{ }^{\circ} \mathrm{C}$ overnight. The precipitates were washed $(3 \mathrm{X})$ in lysis buffer and boiled in SDS-sample buffer containing $100 \mathrm{mM}$ dithiothreitol (DTT). Whole cell lysates as well as immunoprecipitates were subjected to Western blotting analysis using CD44v6, MDR1, and YB-1 antibodies and were detected as above. 


\subsection{Plasmids and Reporter Assays}

Expression vectors: pDSET YBX-1 pDESTmycYBX1 was a gift from Thomas Tuschl (Addgene plasmid \# 19878; http:/ / n2t.net/addgene:19878; RRID:Addgene_19878); pcDNA3cmyc was a gift from Wafik El-Deiry Addgene plasmid \# 16011; http:/ /n2t.net/addgene: 16011; RRID:Addgene_16011); pTK-TWIST was a gift from Bob Weinberg (Addgene plasmid \# 36977; http:/ /n2t.net/addgene:36977; RRID:Addgene_36977); pGEM-OCT4 was a gift from James Thomson (Addgene plasmid \# 16352; http:/ / n2t.net/addgene:16352; RRID:Addgene_16352); SOX2 (Origene) CD44v6 specific PCR amplification products were isolated with polyadenylated RNA from the HT29 cell line. The PCR product was cloned in pcDNA3.1 vector and used as previously described [58].

\subsubsection{Reporter Vectors}

The MDR1 and CD44v6 reporter constructs were synthesized by Bio basic (US) and cloned into the firefly pGL3-basic vector (Promega, Madison, WI, USA)) upstream of the Luciferase reporter gene. The constructs were named as follows: (1) mdr1 (1) contains the basal promoter $(-2300 /+1)$; (2) mdr1 (2) contains promoter site $(-500 /+1)$. Both of the MDR1 promoter constructs contain multiple YB-1 binding sites. For the CD44v6 promoter, the constructs were named as follows: (1) CD44v6 (1) contains promoter site $(-2000 /+1)$; (2) CD44v6 (2) contains promoter site $(-700 /+1)$. Both of the CD44v6 promoter constructs contain multiple YB-1 binding sites. The M50 Super 8x TOPFlash vector (plasmid 12456) with a luciferase gene under the control of seven TCF/LEF-binding sites, and the corresponding M51 Super 8x FOPFlash vector (plasmid 12457) with mutated TCF/LEFbinding sites were obtained from Addgene (Cambridge, MA, USA). The normalization vector $\mathrm{pRL}-\mathrm{TK}$ Renilla with a HSV-TK promotor driving Renilla luciferase was purchased from Promega (Madison, WI, USA).

\subsubsection{Transient Transfection and Luciferase Reporter Assay}

For the transient assays, $1.0 \times 10^{5}$ cells from both cell lines were cotransfected using Lipofectamine LTX 2000 (Invitrogen, (Carlsbad, CA, USA)) with $1 \mu \mathrm{g}$ of each Luciferase construct and 100 ng of pRL-SV40 vector (Promega), according to the manufacturers' instructions. Firefly and Renilla Luciferase activities were measured in cell lysates $48 \mathrm{~h}$ after transfection using the DualGlo Luciferase Assay System (Promega, Madison, WI, USA) on a Veritas TM Microplate Luminometer (Perkin Elmer, Waltham, MA, USA) following the manufacturer's protocol. All experiments were done in triplicate. Ratios of Renilla luciferase readings to firefly luciferase readings were taken for each experiment, and triplicates were averaged. The average values of the tested constructs were normalized to the activity of the empty pGL3-basic vector, which was arbitrarily set at value 1 .

\subsection{3. $\beta$-Catenin/TCF Reporter Assays}

All reporter gene assays were done in 96-well plates. Sensitive and resistant SW948 and HT29 cells $\left(1.0 \times 10^{4} /\right.$ well) were transfected with SuperTOPFLASH reporter ( $\left.25 \mathrm{ng}\right)$ and TK-Renilla (5 $\mathrm{ng}$ ), and with the respective plasmid DNA as indicated using Lipofectamine ${ }^{\mathrm{TM}} 3000$ transfection reagent (Invitrogen, (Carlsbad, CA, USA) according to the manufacturer's protocol. Each transfection was adjusted to $150 \mathrm{ng}$ DNA/transfection with pcDNA3.1 empty vector. Where indicated, cells were transfected at $50-70 \%$ confluency with shRNA constructs using Lipofectamine ${ }^{\mathrm{TM}} 3000$ transfection Reagent in $6 \mathrm{~cm}$ petri dishes according to the manufacturer's protocol $24 \mathrm{~h}$ before seeding the cells for the reporter assays. Then, $50 \mathrm{ng} / \mathrm{mL}$ of WNT3A was added $24 \mathrm{~h}$ after DNA transfection. Cells were lysed $72 \mathrm{~h}$ after DNA transfection with $1 \times$ Passive Lysis Buffer (Promega), and the luciferase activity was measured using the Luminescence counter (PerkinElmer, Waltham, MA, USA). TOPFLASH experiments were normalized to cotransfected Renilla gene expression. 


\subsection{Primer Design and $P C R$}

- $\quad$ RNA extraction and cDNA synthesis [177]

Harvested cells were transferred to $1.5 \mathrm{~mL}$ Eppendorf tubes with a small amount of 1x PBS, and $1 \mathrm{~mL}$ of TRIzol (Invitrogen, Carlsbad, CA, USA) was added. After vortexing, the tube was kept in room temperature for $5 \mathrm{~min}$. Then, $200 \mu \mathrm{L}$ chloroform was added and left at room temperature for $10 \mathrm{~min}$. The tube was centrifuged at $1300 \mathrm{rpm}$ for $15 \mathrm{~min}$ at $4{ }^{\circ} \mathrm{C}$. The upper phase containing RNA was transferred to a new tube, and $600 \mu \mathrm{L}$ ice cold isopropanol was added. The tube was inverted several times, kept in ambient temperature for $10 \mathrm{~min}$, and centrifuged at $1200 \mathrm{rpm}$ for $13 \mathrm{~min}$ at $4{ }^{\circ} \mathrm{C}$. After removing the supernatant, the white RNA pellet was washed with $1 \mathrm{~mL}$ of $75 \%$ alcohol and left air-dried. Then, the sample was dissolved in $50 \mu \mathrm{L}$ DEPC-treated water. The quality and quantity of extracted RNA was checked by a spectrophotometer. The extract was electrophoresed on $1 \%$ agarose gel. DNA contamination was removed from all RNA samples by treating the samples with DNAase. Then, $500 \mathrm{ng}$ of RNA was used for cDNA synthesis. In total, $1 \mu \mathrm{L}$ primer, $1 \mu \mathrm{L}$ buffer $(5 \mathrm{x}), 0.5 \mu \mathrm{L}$ RNase inhibitor, $1 \mu \mathrm{L}$ dNTP $(10 \mathrm{mM})$, and $0.5 \mu \mathrm{L}$ Reverse Transcriptase (Thermo Fisher scientific) were mixed in a microtube $(0.2 \mathrm{~mL})$. The synthesis was performed at $50{ }^{\circ} \mathrm{C}$ for $60 \mathrm{~min}$ in a thermal cycler (BioRad).

- Primer design and semiquantitative RT-PCR [177]

Primers were designed by online Primer Quest Tool (https:/ / eu.idtdna.com). The quality of designed primers was analyzed by OligoAnalyzer Tool software. The semiquantitative PCR primer sequences used for CD44 exon specific PCR are given in Supplemental Table S1, and the primer sequences used in analyses of various genes are discussed in Section 4.15. Semiquantitative PCR was done using different amounts of cDNA of RNA samples. In total, $1 \mu \mathrm{L}$ forward (F) and reverse (R) primers were used. For each sample, PCR was repeated three times. Each reaction contained $1 \mu \mathrm{L}$ of a cDNA sample, $0.5 \mu \mathrm{L}$ of a primer, $5 \mu \mathrm{L}$ Taq DNA Polymerase $2 \times$ Master Mix Red (Amplicon Co., Brighton, $\mathrm{UK}$ ), and $3 \mu \mathrm{L}$ of water in a final volume of $10 \mu \mathrm{L}$. Before the main reactions, the PCR conditions, including thermal conditions, the number of cycles, and the cDNA concentrations, were optimized. During the main PCR cycles, temperature conditions, including one initial denaturation cycle $\left(3 \mathrm{~min}\right.$ at $\left.95^{\circ} \mathrm{C}\right)$, was followed by 35 cycles with a denaturation step for $5 \mathrm{~s}$ at $95{ }^{\circ} \mathrm{C}$ and a combined annealing and extension step for $35 \mathrm{~s}$ at $61{ }^{\circ} \mathrm{C}$. The PCR products were electrophoresed on $2.5 \%$ agarose, stained with ethidium bromide, and photographed. The analysis of band intensities was done by ImageJ software.

\subsection{Quantitative Real-Time RT-PCR (QPCR)}

Total RNA was isolated from cells after various treatments and transfections as described in the figure legends for each specified experiment using the RNeasy mini kit (Qiagen, Beverly, MA, USA) according to the standard protocol provided by the manufacturer, with on-column DNA digestion. RNA integrity and concentration were analyzed using Bioanalyzer, and $100 \mathrm{ng}$ of RNA was retrotranscribed into cDNA using the First Strand cDNA synthesis kit from Roche Applied Science. SYBR Green technology (Bio-Rad, Thermo Fisher, Waltham, MA, USA) was used for all real-time PCR experiments. Amplification was done with the real-time PCR analyzer (Bio-Rad cfx96). The PCR mixture ( $25 \mu \mathrm{L})$ contained $12.5 \mu \mathrm{L}$ of 2 SYBR Green PCR Master Mix (Bio-Rad), $5 \mu \mathrm{L}$ of diluted RT product (1:20), and $0.5 \mu \mathrm{M}$ sense and antisense primer sets. The real-time PCR assays were done in three individual experiments with duplicate samples using standard conditions in a CFX96 real-time PCR detection machine. After incubations at $95^{\circ} \mathrm{C}$ for $3 \mathrm{~min}$, the amplification protocol consisted of 50 cycles of denaturing at $95^{\circ} \mathrm{C}$ for $10 \mathrm{~s}$, annealing, and extension at $60^{\circ} \mathrm{C}$ for $30 \mathrm{~s}$. The standard curve was made from a series dilution of template cDNA. Expression levels of tested genes were calculated after normalization with the housekeeping gene GAPDH. Primer sequences used in QPCR are presented in Table 2. 
Table 2. Real-time PCR (QPCR) primers for various genes used in this study.

\begin{tabular}{|c|c|c|}
\hline \multirow{2}{*}{ Genes } & \multicolumn{2}{|c|}{ Primers } \\
\hline & Forward Sequence $\left(5^{\prime}-3^{\prime}\right)$ & Reverse Sequence $\left(5^{\prime}-3^{\prime}\right)$ \\
\hline NFkB & GTGACAGGAGACGTGAAGATG & TGAAGGTGGATGATTGCTAAGT \\
\hline E2F1 & TCCCTGAGCTGTTCTTCTG & ССТСССТСАСТТТСССААТААА \\
\hline STAT3 & GAGAAGGACATCAGCGGTAAG & CAGTGGAGACACCAGGATATTG \\
\hline RUNX2 & CGGAATGCCTCTGCTGTTAT & TGTGAAGACGGTTATGGTCAAG \\
\hline Snail & ACTATGCCGCGCTCTTTC & GCTGGAAGGTAAACTCTGGATTA \\
\hline TWIST1 & AGACTCTGGAGCTGGATAACT & GCCTGTCTCGCTTTCTCTTT \\
\hline SOX2 & GGACTGAGAGAAAGAAGAGGAGAG & CGCCGCCGATGATTGTTATTA \\
\hline Cyclin D1 & GGTTCAACCCACAGCTACTT & CAGCGCTATTTCCTACACCTATT \\
\hline FZD1 & AAGACCGAGTGGTGTGTAATG & TGGCCATGCTGAAGAAGTAG \\
\hline GINS1 & TCAGGTGGACGAAGTGATTTG & CGAAGCAAGCGGTCATACA \\
\hline MMP9 & GAACTTTGACAGCGACAAGAAG & CGGCACTGAGGAATGATCTAA \\
\hline Lgr5 & GGGAAACGCTCTGACATACA & CTTCTGTGGGTACGTGTCTTAG \\
\hline OCT4 & GGAGGAAGCTGACAACAATGA & СTCTCACTCGGTTCTCGATACT \\
\hline c-Myc & AAGCTGAGGCACACAAAGA & GCTTGGACAGGTTAGGAGTAAA \\
\hline EpCAM & AGCTGGTGTTATTGCTGTTATTG & GCATCTCACССАТСТССТTТАT \\
\hline ALDH1 & CTTGGAATTTCCCGTTGGTTATG & GAGAGCAGTGAGAGGAGTTTG \\
\hline Nanog & GCCTGTAGTCCCAGCTATTTG & GGAGTGCAGTGGTGTGATATT \\
\hline ZEB1 & GGCTCCTATAGCTCACACATAAG & TGCTGAAAGAGACGGTGAAG \\
\hline CD44v6 & GACAGAATCCCTGCTACCAATAG & TCCTTCGTGTGTGGGTAATG \\
\hline
\end{tabular}

\subsection{Chromatin Immunoprecipitation (ChIP) Assay}

The chromatin immunoprecipitation (ChIP) assay was done using the ChIP assay kit (Upstate Biotechnology) following the manufacturer's directions as described [58]. After crosslinking with formaldehyde, nuclear fractions from SW948-FR/SQ/CICs were immunoprecipitated with $5 \mu \mathrm{g}$ of anti-CD44v6 or anti-YB-1 antibody, or with $1 \mu \mathrm{g}$ of normal mouse IgG for $3 \mathrm{~h}$. Chromosomal DNAs were purified and analyzed using semiquantitative PCR to detect the MDR1 and the CD44v6 promoter regions (Figure 6D for MDR1, and Figure 6I for CD44v6 promoters). Nuclear CD44v6, or YB-1-associated chromatins from v6 Mu1, YB-1 Mu3, and Vector transfected SW948-FR CICs were immunoprecipitated with YB-1 or CD44v6 antibodies for $3 \mathrm{~h}$. Chromosomal DNAs were purified and analyzed using QPCR with primers for YB-1 sites of MDR1 (Figure 6F) to detect the MDR1 promoter regions. Similarly, nuclear CD44v6, or YB-1-associated chromatins from V6 Mu1, YB-1 Mu3, and Vector transfected SW948-FR CICs were immunoprecipitated with YB-1 or CD44v6 antibodies for $3 \mathrm{~h}$. Chromosomal DNAs were purified and analyzed using QPCR with primers for YB-1 sites of CD44v6 (Figure 6K) to detect the CD44v6 promoter regions. Control IgGs were used as negative controls for immunoprecipitation. Chromatin inputs were used as loading controls for PCR. The primers used for ChIP PCR studies are presented in Table S3.

\subsection{In Vivo Tumorigenic Potential of CICs}

All animal studies described were approved by the IACUC protocol (\# IACUC-201900829 approved till 09/24/2022) from the Medical University of South Carolina and conducted in accordance with the National Institutes of Health Guide for the Care and Use of Animals. The nonobese diabetic/severe combined immunodeficient (NOD/SCID) female 
mice weighing $\approx 25 \mathrm{~g}$ and aged $\approx 5-6$ weeks were obtained from the Jackson Laboratory and was used for the in vivo experiments. v6-Mu1 and YB-1 Mu3 knockout SW948FR CICs were collected at $5 \times 10^{5}$ cells $/ \mathrm{mL}$ in physiological saline. Matrigel (Becton, Dickinson) was added to the cell suspension at a ratio of $1: 2$, and $200 \mu \mathrm{L}$ of the cell suspension was subcutaneously injected into mice to induce tumor growth. The tumor sizes were measured by a caliper every 5 days, and tumor volume was calculated as (length $(\mathrm{mm}) \times$ width $(\mathrm{mm}) \times$ width $(\mathrm{mm})) / 2$. Sixty days later, the mice were sacrificed, and the solid tumors were collected. The tumor sizes and weights were examined to evaluate the tumor development (Figure 7A,B). Total RNAs extracted from the fresh tumors were processed for QPCR analysis for Cyclin D1, BCL2, FZD1, GINS1, and MMP9 (Figure 7D). Tumor lysates were analyzed for CD44v6, YB-1 and MDR1 by Western blot analyses (Figure 7C).

\subsection{Statistics}

A two-tailed Student's $t$-test was used to compare mean values between sensitive and resistant cells using the following parameters: mean $\Delta \Delta C T$ values for QPCR; mean colony number for soft agar growth assays; mean densitometry values for QPCR and WB; mean percentage of cell viability assay (Cell Titer-Glo) and FACS analysis; mean luminescence for ATP activity in cell growth, Caspase Glow assays in apoptosis measurements; mean tumor weights in xenograft studies. Chi-squared analysis was performed to compare incidences between sensitive and resistant cells for the following assays: number of positive wells containing tumor spheres in the sphere formation assay; numbers of mice developing tumors in xenograft studies. For experiments involving three or more groups, statistical significance was calculated with GraphPad Prism Software v.8 (San Diego, CA, USA) using a 1-way or 2-way ANOVA with a Bonferroni's posttest, Student's $t$ test, or log-rank (Mantel-Cox) test where appropriate (GraphPad Prism Software v.8 (San Diego, CA, USA). Data are represented as the mean $\pm \mathrm{SD}$.

\section{Conclusions}

In conclusion, collectively, our data (Figure 8) indicate that (1) FOLFOX therapy induces overexpression of CD44v6, and of YB-1, a key oncogenic transcription factor to maintain stemness of CRC CICs; (2) our data link CD44v6-induced PGE2 with mTOR signaling to induce YB-1 expression; (3) we identified a novel function for CD44v6 in transcriptional modulation through nuclear translocation of CD44v6 and complex formation with stemness-associated transcription factors, including YB-1 in CICs, where YB-1 exerted its specific functions in cancer initiating cells via CD44v6 and MDR1 DNA transcription. As a result, a positive feedback loop couples YB-1 activation and CD44 alternative splicing to sustain CD44v6 and FOLFOX resistance through MDR1 expression; (4) in addition, we demonstrated that YB-1 is associated with CD44v6 in a nuclear complex. In CD44v6 Mu1 SW948-FR CICs, ectopic expression of the YB-1, and CD44v6-rescue plasmids enhanced expression of proliferation/anti-apoptosis/invasion/stemness associated Cyclin D1, BCL2, FZD1, GINS-1, and MMP9 genes providing evidence that CD44v6-elicited expressions of stemness related genes are mediated through CD44v6 and YB-1([178], (Supplemental Table S2); (5) CD44v6-YB-1 signaling has an essential role in the activation and reversion of the pluripotency of differentiated cancer cells; (6) owing to their potential roles in chemoresistance, targeting CD44v6 significantly reduces tumor formation in vitro and in vivo. Thus, CD44v6 signaling could be a potential therapeutic target molecule combined with conventional chemotherapy to elevate the chemosensitivity of CRC (Figure 8). 



Positive feedback loop between CD44v6 and YB-1 controls CD44v6 (+) CIC,s expansion, stemness, and drug resistance function



Niche Programming at and Tumor regression

Secondary Site, Stemness

Acquisition and drug resistance

"CTOS" (cMyc, TWIST1, OCT4, SOX2) plus (CD44v6 rescue plasmid, or YB-1 WT plasmid overexpression)
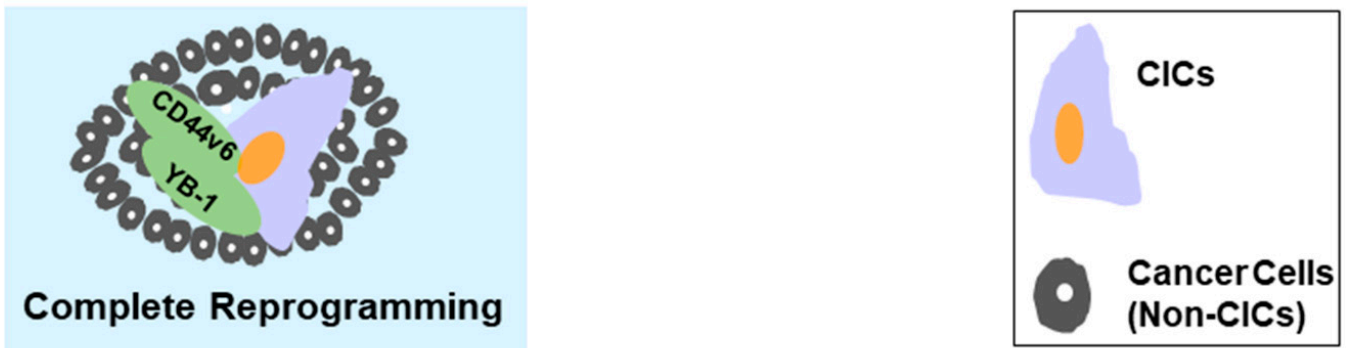

Figure 8. Proposed model for a positive feedback loop coupling YB-1 activation and CD44 alternate splicing and CD44v6 then sustains cancer initiating cell proliferation and stemness.

Supplementary Materials: The following are available online at https:/ / www.mdpi.com/1422-006 7/22/2/753/s1.

Author Contributions: The experiments of this work were designed and carried out by S.M. and S.G. The paper was written by S.M. and S.G. V.C.H. and R.R.M. reviewed, edited the multiple versions of the drafts and final versions of the text, figures, figure legends, and supplied reagents. All authors have read and agreed to the published version of the manuscript. 
Funding: This work was supported by the (1) 1R03CA167722-01A1 (to SM (PI) and SG (Co-I), 04/01/2013 to 03/302015); (2) 1K12HL141952-02 (to V. C. H. [Co-PI]: 6/1/18 to 5/31/23); (3) 2P20GM10399 (R Markwald, MUSC PI; 09/01/20-06/30/25); NIH IDeA Network for SC Biomedical Research Excellence, (4) 2 P30 GM131959-01 (R Markwald, MUSC PI; 07/01/20-6/30/25), (5) 19TPA34900016 (R Markwald, MUSC PI; 7/1/2019-6/30/2022). The costs of publication of this article will be defrayed in part by the payment of page charges. This article must therefore be hereby marked 'advertisement' in accordance with 18 U.S.C. Section 1734 solely to indicate this fact.

Institutional Review Board Statement: The IRB has determined that this research project meets the criteria for 'Non Human Subjects' research.

Informed Consent Statement: All authors have seen the manuscript and approved its content.

Data Availability Statement: The datasets generated during the current study are not publicly available because the data are used in the manuscript and in funding opportunity.

Conflicts of Interest: The authors declare that they have no conflict of interest with the contents of this article.

$\begin{array}{ll}\text { Abbreviations } \\ \text { CD44s } & \text { Standard isoform of CD44 having no variant exons } \\ \text { CD44v } & \text { CD44 splice variant } \\ \text { CD44v6 } & \text { variant } 6 \text { of CD44 } \\ \text { v6 } & \text { CD44v6 } \\ \text { sh } & \text { shRNA } \\ \text { v6 Mu1 } & \text { v6 knockout Mu1 } \\ \text { v6 Mu2 } & \text { v6 knockout Mu2 } \\ \text { YB-1 Mu3 } & \text { YB-1 knockout Mu3 } \\ \text { YB-1 Mu4 } & \text { YB-1 knockout Mu4 } \\ \text { CIC } & \text { Cancer initiating cell } \\ \text { CRC } & \text { Colorectal cancer } \\ \text { 5-FU } & \text { 5-Fluorouracil } \\ \text { OXA } & \text { Oxaliplatin } \\ \text { FOLFOX } & \text { 5-FU pls OXA plus leucovorin } \\ \text { ALDH1 } & \text { Aldehyde dehydrogenase 1 } \\ \text { MDR1 } & \text { Multidrug-resistance protein 1 } \\ \text { IP } & \text { Immunoprecipitation } \\ \text { YB-1 } & \text { Y-box binding protein-1 } \\ \text { WB } & \text { Western blotting } \\ \text { SQ } & \text { Subcutaneous } \\ \text { CTOS } & \text { c-Myc, TWIST1, OCT4, and SOX2 } \\ \text { TF } & \text { Transcription factors }\end{array}$

\section{References}

1. Siegel, R.L.; Miller, K.D.; Fedewa, S.A.; Ahnen, D.J.; Meester, R.G.S.; Barzi, A.; Jemal, A. Colorectal cancer statistics, 2017. CA Cancer J. Clin. 2017, 67, 177-193. [CrossRef]

2. Siegel, R.L.; Miller, K.D.; Jemal, A. Cancer statistics, 2016. CA Cancer J. Clin. 2016, 66, 7-30. [CrossRef]

3. Cunningham, D.; Atkin, W.; Lenz, H.J.; Lynch, H.T.; Minsky, B.; Nordlinger, B.; Starling, N. Colorectal cancer. Lancet 2010, 375, 1030-1047. [CrossRef]

4. Winawer, S.J. Screening of colorectal cancer. Surg. Oncol. Clin. N. Am. 2005, 14, 699-722. [CrossRef] [PubMed]

5. Winawer, S.J.; Zauber, A.G.; Ho, M.N.; O’Brien, M.J.; Gottlieb, L.S.; Sternberg, S.S.; Waye, J.D.; Schapiro, M.; Bond, J.H.; Panish, J.F.; et al. Prevention of colorectal cancer by colonoscopic polypectomy. N. Engl. J. Med. 1993, 329, 1977-1981. [CrossRef] [PubMed]

6. Dallas, N.A.; Xia, L.; Fan, F.; Gray, M.J.; Gaur, P.; van Buren, G., II; Samuel, S.; Kim, M.P.; Lim, S.J.; Ellis, L.M. Chemoresistant colorectal cancer cells, the cancer stem cell phenotype, and increased sensitivity to insulin-like growth factor-I receptor inhibition. Cancer Res. 2009, 69, 1951-1957. [CrossRef] [PubMed]

7. Kelland, L. The resurgence of platinum-based cancer chemotherapy. Nat. Rev. Cancer 2007, 7, 573-584. [CrossRef] 
8. Zhou, M.; Yu, P.; Davin, D.B.H.; Li, Y.; Wang, Y.; Fu, L.; Zhang, J. Is FOLFOXIRI alone or combined with targeted therapy administered as first-line treatment a reasonable choice for most patients with mCRC? Systematic review and network metaanalysis. Oncotarget 2017, 8, 62339-62348. [CrossRef]

9. Rothenberg, M.L. Efficacy of oxaliplatin in the treatment of colorectal cancer. Oncology 2000, 14, 9-14.

10. Singh, A.K.; Arya, R.K.; Maheshwari, S.; Singh, A.; Meena, S.; Pandey, P.; Dormond, O.; Datta, D. Tumor heterogeneity and cancer stem cell paradigm: Updates in concept, controversies and clinical relevance. Int. J. Cancer 2015, 136, 1991-2000. [CrossRef]

11. Valent, P.; Bonnet, D.; De Maria, R.; Lapidot, T.; Copland, M.; Melo, J.V.; Chomienne, C.; Ishikawa, F.; Schuringa, J.J.; Stassi, G.; et al. Cancer stem cell definitions and terminology: The devil is in the details. Nat. Rev. Cancer 2012, 12, 767-775. [CrossRef] [PubMed]

12. Rich, J.N. Cancer stem cells: Understanding tumor hierarchy and heterogeneity. Medicine 2016, 95, S2-S77. [CrossRef] [PubMed]

13. Vermeulen, L.; De Sousa, E.M.F.; van der Heijden, M.; Cameron, K.; de Jong, J.H.; Borovski, T.; Tuynman, J.B.; Todaro, M.; Merz, C.; Rodermond, H.; et al. Wnt activity defines colon cancer stem cells and is regulated by the microenvironment. Nat. Cell Biol. 2010, 12, 468-476. [CrossRef] [PubMed]

14. Vermeulen, L.; Sprick, M.R.; Kemper, K.; Stassi, G.; Medema, J.P. Cancer stem cells—Old concepts, new insights. Cell Death Differ. 2008, 15, 947-958. [CrossRef] [PubMed]

15. Al-Hajj, M.; Wicha, M.S.; Benito-Hernandez, A.; Morrison, S.J.; Clarke, M.F. Prospective identification of tumorigenic breast cancer cells. Proc. Natl. Acad. Sci. USA 2003, 100, 3983-3988. [CrossRef]

16. Singh, S.K.; Clarke, I.D.; Terasaki, M.; Bonn, V.E.; Hawkins, C.; Squire, J.; Dirks, P.B. Identification of a cancer stem cell in human brain tumors. Cancer Res. 2003, 63, 5821-5828.

17. Fang, D.; Nguyen, T.K.; Leishear, K.; Finko, R.; Kulp, A.N.; Hotz, S.; Van Belle, P.A.; Xu, X.; Elder, D.E.; Herlyn, M. A tumorigenic subpopulation with stem cell properties in melanomas. Cancer Res. 2005, 65, 9328-9337. [CrossRef]

18. Tirino, V.; Desiderio, V.; d'Aquino, R.; De Francesco, F.; Pirozzi, G.; Graziano, A.; Galderisi, U.; Cavaliere, C.; De Rosa, A.; Papaccio, G.; et al. Detection and characterization of CD133+ cancer stem cells in human solid tumours. PLoS ONE 2008, 3, e3469. [CrossRef]

19. Tirino, V.; Desiderio, V.; Paino, F.; De Rosa, A.; Papaccio, F.; Fazioli, F.; Pirozzi, G.; Papaccio, G. Human primary bone sarcomas contain CD133+ cancer stem cells displaying high tumorigenicity in vivo. FASEB J. 2011, 25, 2022-2030. [CrossRef]

20. Collins, A.T.; Berry, P.A.; Hyde, C.; Stower, M.J.; Maitland, N.J. Prospective identification of tumorigenic prostate cancer stem cells Cancer Res. 2005, 65, 10946-10951. [CrossRef]

21. Bapat, S.A.; Mali, A.M.; Koppikar, C.B.; Kurrey, N.K. Stem and progenitor-like cells contribute to the aggressive behavior of human epithelial ovarian cancer. Cancer Res. 2005, 65, 3025-3029. [CrossRef]

22. Takaishi, S.; Okumura, T.; Tu, S.; Wang, S.S.; Shibata, W.; Vigneshwaran, R.; Gordon, S.A.; Shimada, Y.; Wang, T.C. Identification of gastric cancer stem cells using the cell surface marker CD44. Stem Cells 2009, 27, 1006-1020. [CrossRef] [PubMed]

23. Eramo, A.; Lotti, F.; Sette, G.; Pilozzi, E.; Biffoni, M.; Di Virgilio, A.; Conticello, C.; Ruco, L.; Peschle, C.; De Maria, R. Identification and expansion of the tumorigenic lung cancer stem cell population. Cell Death Differ. 2008, 15, 504-514. [CrossRef] [PubMed]

24. Tirino, V.; Camerlingo, R.; Franco, R.; Malanga, D.; La Rocca, A.; Viglietto, G.; Rocco, G.; Pirozzi, G. The role of CD133 in the identification and characterisation of tumour-initiating cells in non-small-cell lung cancer. Eur. J. Cardio-Thorac. Surg. 2009, 36, 446-453. [CrossRef] [PubMed]

25. Wei, B.; Chen, L.; Li, R.; Tian, J. Stem cells in gastrointestinal cancers: A matter of choice in cell fate determination. Expert Rev. Anticancer Ther. 2010, 10, 1621-1633. [CrossRef] [PubMed]

26. Todaro, M.; Alea, M.P.; Di Stefano, A.B.; Cammareri, P.; Vermeulen, L.; Iovino, F.; Tripodo, C.; Russo, A.; Gulotta, G.; Medema, J.P.; et al. Colon cancer stem cells dictate tumor growth and resist cell death by production of interleukin-4. Cell Stem Cell 2007, 1, 389-402. [CrossRef]

27. Todaro, M.; Gaggianesi, M.; Catalano, V.; Benfante, A.; Iovino, F.; Biffoni, M.; Apuzzo, T.; Sperduti, I.; Volpe, S.; Cocorullo, G.; et al. CD44v6 is a marker of constitutive and reprogrammed cancer stem cells driving colon cancer metastasis. Cell Stem Cell 2014, 14, 342-356. [CrossRef]

28. Natarajan, T.G.; Ganesan, N.; Fitzgerald, K.T. Cancer stem cells and markers: New model of tumorigenesis with therapeutic implications. Cancer Biomark. 2010, 9, 65-99. [CrossRef]

29. Prasetyanti, P.R.; Medema, J.P. Intra-tumor heterogeneity from a cancer stem cell perspective. Mol. Cancer 2017, 16, 41. [CrossRef]

30. Sanchez, J.A.; Krumroy, L.; Plummer, S.; Aung, P.; Merkulova, A.; Skacel, M.; DeJulius, K.L.; Manilich, E.; Church, J.M.; Casey, G.; et al. Genetic and epigenetic classifications define clinical phenotypes and determine patient outcomes in colorectal cancer. Br. J. Surg. 2009, 96, 1196-1204. [CrossRef]

31. Sadanandam, A.; Lyssiotis, C.A.; Homicsko, K.; Collisson, E.A.; Gibb, W.J.; Wullschleger, S.; Ostos, L.C.; Lannon, W.A.; Grotzinger, C.; Del Rio, M.; et al. A colorectal cancer classification system that associates cellular phenotype and responses to therapy. Nat. Med. 2013, 19, 619-625. [CrossRef] [PubMed]

32. Ogino, S.; Fuchs, C.S.; Giovannucci, E. How many molecular subtypes? Implications of the unique tumor principle in personalized medicine. Expert Rev. Mol. Diagn. 2012, 12, 621-628. [CrossRef] [PubMed]

33. Hermann, P.C.; Huber, S.L.; Herrler, T.; Aicher, A.; Ellwart, J.W.; Guba, M.; Bruns, C.J.; Heeschen, C. Distinct populations of cancer stem cells determine tumor growth and metastatic activity in human pancreatic cancer. Cell Stem Cell 2007, 1, 313-323. [CrossRef] [PubMed] 
34. Vermeulen, L.; Todaro, M.; Mello, F.d.S.; Sprick, M.R.; Kemper, K.; Alea, M.P.; Richel, D.J.; Stassi, G.; Medema, J.P. Single-cell cloning of colon cancer stem cells reveals a multi-lineage differentiation capacity. Proc. Natl. Acad. Sci. USA 2008, 105, 13427-13432. [CrossRef] [PubMed]

35. Ohata, H.; Ishiguro, T.; Aihara, Y.; Sato, A.; Sakai, H.; Sekine, S.; Taniguchi, H.; Akasu, T.; Fujita, S.; Nakagama, H.; et al. Induction of the stem-like cell regulator CD44 by Rho kinase inhibition contributes to the maintenance of colon cancer-initiating cells. Cancer Res. 2012, 72, 5101-5110. [CrossRef]

36. Hide, T.; Takezaki, T.; Nakamura, H.; Kuratsu, J.; Kondo, T. Brain tumor stem cells as research and treatment targets. Brain Tumor Pathol. 2008, 25, 67-72. [CrossRef]

37. Huang, E.H.; Hynes, M.J.; Zhang, T.; Ginestier, C.; Dontu, G.; Appelman, H.; Fields, J.Z.; Wicha, M.S.; Boman, B.M. Aldehyde dehydrogenase 1 is a marker for normal and malignant human colonic stem cells (SC) and tracks SC overpopulation during colon tumorigenesis. Cancer Res. 2009, 69, 3382-3389. [CrossRef]

38. Phi, L.T.H.; Sari, I.N.; Yang, Y.G.; Lee, S.H.; Jun, N.; Kim, K.S.; Lee, Y.K.; Kwon, H.Y. Cancer Stem Cells (CSCs) in Drug Resistance and their Therapeutic Implications in Cancer Treatment. Stem Cells Int. 2018, 2018, 5416923. [CrossRef]

39. Houthuijzen, J.M.; Daenen, L.G.; Roodhart, J.M.; Voest, E.E. The role of mesenchymal stem cells in anti-cancer drug resistance and tumour progression. Br. J. Cancer 2012, 106, 1901-1906. [CrossRef]

40. Fulda, S. Regulation of apoptosis pathways in cancer stem cells. Cancer Lett. 2013, 338, 168-173. [CrossRef]

41. Blanpain, C. Tracing the cellular origin of cancer. Nat. Cell Biol. 2013, 15, 126-134. [CrossRef] [PubMed]

42. Brabletz, T.; Jung, A.; Spaderna, S.; Hlubek, F.; Kirchner, T. Opinion: Migrating cancer stem cells-An integrated concept of malignant tumour progression. Nat. Rev. Cancer 2005, 5, 744-749. [CrossRef] [PubMed]

43. Screaton, G.R.; Bell, M.V.; Jackson, D.G.; Cornelis, F.B.; Gerth, U.; Bell, J.I. Genomic structure of DNA encoding the lymphocyte homing receptor CD44 reveals at least 12 alternatively spliced exons. Proc. Natl. Acad. Sci. USA 1992, 89, 12160-12164. [CrossRef] [PubMed]

44. Zoller, M. CD44: Can a cancer-initiating cell profit from an abundantly expressed molecule? Nat. Rev. Cancer 2011, 11, 254-267. [CrossRef] [PubMed]

45. Naor, D.; Wallach-Dayan, S.B.; Zahalka, M.A.; Sionov, R.V. Involvement of CD44, a molecule with a thousand faces, in cancer dissemination. Semin. Cancer Biol. 2008, 18, 260-267. [CrossRef]

46. Wang, Z.; Zhao, K.; Hackert, T.; Zoller, M. CD44/CD44v6 a Reliable Companion in Cancer-Initiating Cell Maintenance and Tumor Progression. Front. Cell Dev. Biol. 2018, 6, 97. [CrossRef]

47. Zeilstra, J.; Joosten, S.P.; van Andel, H.; Tolg, C.; Berns, A.; Snoek, M.; van de Wetering, M.; Spaargaren, M.; Clevers, H.; Pals, S.T. Stem cell CD44v isoforms promote intestinal cancer formation in Apc(min) mice downstream of Wnt signaling. Oncogene 2014, 33, 665-670. [CrossRef]

48. Misra, S.; Hascall, V.C.; De Giovanni, C.; Markwald, R.R.; Ghatak, S. Delivery of CD44 shRNA/nanoparticles within cancer cells: Perturbation of hyaluronan/CD44v6 interactions and reduction in adenoma growth in Apc Min/+ MICE. J. Biol. Chem. 2009, 284, 12432-12446. [CrossRef]

49. Misra, S.; Ghatak, S.; Toole, B.P. Regulation of MDR1 expression and drug resistance by a positive feedback loop involving hyaluronan, phosphoinositide 3-kinase, and ErbB2. J. Biol. Chem. 2005, 280, 20310-20315. [CrossRef]

50. Misra, S.; Hascall, V.C.; Berger, F.G.; Markwald, R.R.; Ghatak, S. Hyaluronan, CD44, and cyclooxygenase-2 in colon cancer. Connect. Tissue Res. 2008, 49, 219-224. [CrossRef]

51. Misra, S.; Toole, B.P.; Ghatak, S. Hyaluronan constitutively regulates activation of multiple receptor tyrosine kinases in epithelial and carcinoma cells. J. Biol. Chem. 2006, 281, 34936-34941. [CrossRef] [PubMed]

52. Ghatak, S.; Misra, S.; Toole, B.P. Hyaluronan constitutively regulates ErbB2 phosphorylation and signaling complex formation in carcinoma cells. J. Biol. Chem. 2005, 280, 8875-8883. [CrossRef]

53. Sherman, L.; Wainwright, D.; Ponta, H.; Herrlich, P. A splice variant of CD44 expressed in the apical ectodermal ridge presents fibroblast growth factors to limb mesenchyme and is required for limb outgrowth. Genes Dev. 1998, 12, 1058-1071. [CrossRef] [PubMed]

54. Bourguignon, L.Y.; Gilad, E.; Peyrollier, K. Heregulin-mediated ErbB2-ERK signaling activates hyaluronan synthases leading to CD44-dependent ovarian tumor cell growth and migration. J. Biol. Chem. 2007, 282, 19426-19441. [CrossRef] [PubMed]

55. Orian-Rousseau, V.; Chen, L.; Sleeman, J.P.; Herrlich, P.; Ponta, H. CD44 is required for two consecutive steps in HGF/c-Met signaling. Genes Dev. 2002, 16, 3074-3086. [CrossRef] [PubMed]

56. Tremmel, M.; Matzke, A.; Albrecht, I.; Laib, A.M.; Olaku, V.; Ballmer-Hofer, K.; Christofori, G.; Heroult, M.; Augustin, H.G.; Ponta, H.; et al. A CD44v6 peptide reveals a role of CD44 in VEGFR-2 signaling and angiogenesis. Blood 2009, 114, $5236-5244$. [CrossRef] [PubMed]

57. Ghatak, S.; Hascall, V.C.; Markwald, R.R.; Feghali-Bostwick, C.; Artlett, C.M.; Gooz, M.; Bogatkevich, G.S.; Atanelishvili, I.; Silver, R.M.; Wood, J.; et al. TGF beta-1 induced CD44v6-NOX4 signaling in pathogenesis of idiopathic pulmonary fibrosis. J. Biol. Chem. 2017, 292, 10490-10519. [CrossRef]

58. Ghatak, S.; Markwald, R.R.; Hascall, V.C.; Dowling, W.; Lottes, R.G.; Baatz, J.E.; Beeson, G.; Beeson, C.C.; Perrella, M.A.; Thannickal, V.J.; et al. TGF beta-1 regulates CD44v6 expression and activity through ERK-induced EGR1 in pulmonary fibrogenic fibroblasts. J. Biol. Chem. 2017, 292, 752451. [CrossRef] 
59. Bourguignon, L.Y. CD44-mediated oncogenic signaling and cytoskeleton activation during mammary tumor progression. J. Mammary Gland Biol. Neoplasia 2001, 6, 287-297. [CrossRef]

60. Marhaba, R.; Zoller, M. CD44 in cancer progression: Adhesion, migration and growth regulation. J. Mol. Histol. 2004, 35, $211-231$. [CrossRef]

61. Nishino, M.; Ozaki, M.; Hegab, A.E.; Hamamoto, J.; Kagawa, S.; Arai, D.; Yasuda, H.; Naoki, K.; Soejima, K.; Saya, H.; et al. Variant CD44 expression is enriching for a cell population with cancer stem cell-like characteristics in human lung adenocarcinoma. J. Cancer 2017, 8, 1774-1785. [CrossRef] [PubMed]

62. Zoller, M. Tetraspanins: Push and pull in suppressing and promoting metastasis. Nat. Rev. Cancer 2009, 9, 40-55. [CrossRef] [PubMed]

63. Gherardi, E.; Birchmeier, W.; Birchmeier, C.; Woude, G.V. Targeting MET in cancer: Rationale and progress. Nat. Rev. Cancer 2012, 12, 89-103. [CrossRef] [PubMed]

64. LaTulippe, E.; Satagopan, J.; Smith, A.; Scher, H.; Scardino, P.; Reuter, V.; Gerald, W.L. Comprehensive gene expression analysis of prostate cancer reveals distinct transcriptional programs associated with metastatic disease. Cancer Res. 2002, 62, 4499-4506. [PubMed]

65. Padua, D.; Figueira, P.; Ribeiro, I.; Almeida, R.; Mesquita, P. The Relevance of Transcription Factors in Gastric and Colorectal Cancer Stem Cells Identification and Eradication. Front. Cell Dev. Biol. 2020, 8, 442. [CrossRef]

66. Farabaugh, S.M.; Boone, D.N.; Lee, A.V. Role of IGF1R in Breast Cancer Subtypes, Stemness, and Lineage Differentiation. Front. Endocrinol. 2015, 6, 59. [CrossRef]

67. Perino, M.; Veenstra, G.J. Chromatin Control of Developmental Dynamics and Plasticity. Dev. Cell 2016, 38, 610-620. [CrossRef]

68. Acemel, R.D.; Maeso, I.; Gomez-Skarmeta, J.L. Topologically associated domains: A successful scaffold for the evolution of gene regulation in animals. Wiley Interdiscip Rev Dev Biol. 2017, 6, e265. [CrossRef]

69. Morris, S.A. Direct lineage reprogramming via pioneer factors; a detour through developmental gene regulatory networks. Development 2016, 143, 2696-2705. [CrossRef]

70. Niwa, H. How is pluripotency determined and maintained? Development 2007, 134, 635-646. [CrossRef]

71. Niwa, H. The principles that govern transcription factor network functions in stem cells. Development 2018, 145, dev157420. [CrossRef] [PubMed]

72. Beck, B.; Blanpain, C. Unravelling cancer stem cell potential. Nat. Rev. Cancer 2013, 13, 727-738. [CrossRef] [PubMed]

73. Peinado, H.; Olmeda, D.; Cano, A. Snail, Zeb and bHLH factors in tumour progression: An alliance against the epithelial phenotype? Nat. Rev. Cancer 2007, 7, 415-428. [CrossRef]

74. Nichols, J.; Zevnik, B.; Anastassiadis, K.; Niwa, H.; Klewe-Nebenius, D.; Chambers, I.; Scholer, H.; Smith, A. Formation of pluripotent stem cells in the mammalian embryo depends on the POU transcription factor Oct4. Cell 1998, 95, 379-391. [CrossRef]

75. Niwa, H.; Miyazaki, J.; Smith, A.G. Quantitative expression of Oct-3/4 defines differentiation, dedifferentiation or self-renewal of ES cells. Nat. Genet. 2000, 24, 372-376. [CrossRef]

76. Avilion, A.A.; Nicolis, S.K.; Pevny, L.H.; Perez, L.; Vivian, N.; Lovell-Badge, R. Multipotent cell lineages in early mouse development depend on $\mathrm{SOX}_{2}$ function. Genes Dev. 2003, 17, 126-140. [CrossRef]

77. Chambers, I.; Colby, D.; Robertson, M.; Nichols, J.; Lee, S.; Tweedie, S.; Smith, A. Functional expression cloning of Nanog, a pluripotency sustaining factor in embryonic stem cells. Cell 2003, 113, 643-655. [CrossRef]

78. Mitsui, K.; Tokuzawa, Y.; Itoh, H.; Segawa, K.; Murakami, M.; Takahashi, K.; Maruyama, M.; Maeda, M.; Yamanaka, S. The homeoprotein Nanog is required for maintenance of pluripotency in mouse epiblast and ES cells. Cell 2003, 113, 631-642. [CrossRef]

79. Takahashi, K.; Yamanaka, S. Induction of pluripotent stem cells from mouse embryonic and adult fibroblast cultures by defined factors. Cell 2006, 126, 663-676. [CrossRef]

80. Matsuda, T.; Nakamura, T.; Nakao, K.; Arai, T.; Katsuki, M.; Heike, T.; Yokota, T. STAT3 activation is sufficient to maintain an undifferentiated state of mouse embryonic stem cells. EMBO J. 1999, 18, 4261-4269. [CrossRef]

81. Niwa, H.; Burdon, T.; Chambers, I.; Smith, A. Self-renewal of pluripotent embryonic stem cells is mediated via activation of STAT3. Genes Dev. 1998, 12, 2048-2060. [CrossRef] [PubMed]

82. Kielman, M.F.; Rindapaa, M.; Gaspar, C.; van Poppel, N.; Breukel, C.; van Leeuwen, S.; Taketo, M.M.; Roberts, S.; Smits, R.; Fodde, R. Apc modulates embryonic stem-cell differentiation by controlling the dosage of beta-catenin signaling. Nat. Genet. 2002, 32, 594-605. [CrossRef] [PubMed]

83. Sato, N.; Meijer, L.; Skaltsounis, L.; Greengard, P.; Brivanlou, A.H. Maintenance of pluripotency in human and mouse embryonic stem cells through activation of Wnt signaling by a pharmacological GSK-3-specific inhibitor. Nat. Med. 2004, 10, 55-63. [CrossRef] [PubMed]

84. Humphries, H.N.; Wickremesekera, S.K.; Marsh, R.W.; Brasch, H.D.; Mehrotra, S.; Tan, S.T.; Itinteang, T. Characterization of Cancer Stem Cells in Colon Adenocarcinoma Metastasis to the Liver. Front. Surg. 2017, 4, 76. [CrossRef]

85. Deng, J.J.; Zhang, W.; Xu, X.M.; Zhang, F.; Tao, W.P.; Ye, J.J.; Ge, W. Twist mediates an aggressive phenotype in human colorectal cancer cells. Int. J. Oncol. 2016, 48, 1117-1124. [CrossRef] [PubMed]

86. Lyabin, D.N.; Eliseeva, I.A.; Ovchinnikov, L.P. YB-1 protein: Functions and regulation. Wiley Interdiscip. Rev. RNA 2014, 5, 95-110. [CrossRef]

87. Lasham, A.; Print, C.G.; Woolley, A.G.; Dunn, S.E.; Braithwaite, A.W. YB-1: Oncoprotein, prognostic marker and therapeutic target? Biochem. J. 2013, 449, 11-23. [CrossRef] 
88. Kosnopfel, C.; Sinnberg, T.; Schittek, B. Y-box binding protein 1-A prognostic marker and target in tumour therapy. Eur. J. Cell Biol. 2014, 93, 61-70. [CrossRef]

89. Harada, M.; Kotake, Y.; Ohhata, T.; Kitagawa, K.; Niida, H.; Matsuura, S.; Funai, K.; Sugimura, H.; Suda, T.; Kitagawa, M. YB-1 promotes transcription of cyclin D1 in human non-small-cell lung cancers. Genes Cells 2014, 19, 504-516. [CrossRef]

90. Zhang, X.; Ding, Z.; Mo, J.; Sang, B.; Shi, Q.; Hu, J.; Xie, S.; Zhan, W.; Lu, D.; Yang, M.; et al. GOLPH3 promotes glioblastoma cell migration and invasion via the mTOR-YB1 pathway in vitro. Mol. Carcinog. 2015, 54, 1252-1263. [CrossRef]

91. Wu, Y.; Wang, K.Y.; Li, Z.; Liu, Y.P.; Izumi, H.; Yamada, S.; Uramoto, H.; Nakayama, Y.; Ito, K.; Kohno, K. Y-box binding protein 1 expression in gastric cancer subtypes and association with cancer neovasculature. Clin. Transl. Oncol. 2015, 17, 152-159. [CrossRef]

92. Jung, K.; Wu, F.; Wang, P.; Ye, X.; Abdulkarim, B.S.; Lai, R. YB-1 regulates Sox 2 to coordinately sustain stemness and tumorigenic properties in a phenotypically distinct subset of breast cancer cells. BMC Cancer 2014, 14, 328. [CrossRef]

93. Wu, Y.; Yamada, S.; Izumi, H.; Li, Z.; Shimajiri, S.; Wang, K.Y.; Liu, Y.P.; Kohno, K.; Sasaguri, Y. Strong YB-1 expression is associated with liver metastasis progression and predicts shorter disease-free survival in advanced gastric cancer. J. Surg. Oncol. 2012, 105, 724-730. [CrossRef] [PubMed]

94. Ardito, F.; Arena, V.; Vellone, M.; Grande, G.; Pennacchia, I.; Majellaro, F.; Giovannini, I.; Vecchio, F.M.; Nuzzo, G.; Giuliante, F. Strong YB-1 expression predicts liver recurrence following resection for colorectal metastases. J. Gastrointest. Surg. 2014, 18, 1987-1993. [CrossRef] [PubMed]

95. Yan, X.; Yan, L.; Zhou, J.; Liu, S.; Shan, Z.; Jiang, C.; Tian, Y.; Jin, Z. High expression of Y-box-binding protein 1 is associated with local recurrence and predicts poor outcome in patients with colorectal cancer. Int. J. Clin. Exp. Pathol. 2014, 7, 8715-8723.

96. To, K.; Fotovati, A.; Reipas, K.M.; Law, J.H.; Hu, K.; Wang, J.; Astanehe, A.; Davies, A.H.; Lee, L.; Stratford, A.L.; et al. Ybox binding protein-1 induces the expression of CD44 and CD49f leading to enhanced self-renewal, mammosphere growth, and drug resistance. Cancer Res. 2010, 70, 2840-2851. [CrossRef] [PubMed]

97. Hong, S.P.; Wen, J.; Bang, S.; Park, S.; Song, S.Y. CD44-positive cells are responsible for gemcitabine resistance in pancreatic cancer cells. Int. J. Cancer 2009, 125, 2323-2331. [CrossRef] [PubMed]

98. Evdokimova, V.; Tognon, C.; Ng, T.; Ruzanov, P.; Melnyk, N.; Fink, D.; Sorokin, A.; Ovchinnikov, L.P.; Davicioni, E.; Triche, T.J.; et al. Translational activation of snail1 and other developmentally regulated transcription factors by YB-1 promotes an epithelialmesenchymal transition. Cancer Cell 2009, 15, 402-415. [CrossRef] [PubMed]

99. Bargou, R.C.; Jurchott, K.; Wagener, C.; Bergmann, S.; Metzner, S.; Bommert, K.; Mapara, M.Y.; Winzer, K.J.; Dietel, M.; Dorken, B.; et al. Nuclear localization and increased levels of transcription factor YB-1 in primary human breast cancers are associated with intrinsic MDR1 gene expression. Nat. Med. 1997, 3, 447-450. [CrossRef] [PubMed]

100. Misra, S.; Ghatak, S.; Zoltan-Jones, A.; Toole, B.P. Regulation of multidrug resistance in cancer cells by hyaluronan. J. Biol. Chem. 2003, 278, 25285-25288. [CrossRef] [PubMed]

101. Bourguignon, L.Y.; Earle, C.; Wong, G.; Spevak, C.C.; Krueger, K. Stem cell marker (Nanog) and Stat-3 signaling promote MicroRNA-21 expression and chemoresistance in hyaluronan/CD44-activated head and neck squamous cell carcinoma cells. Oncogene 2012, 31, 149-160. [CrossRef]

102. Misra, S.; Obeid, L.M.; Hannun, Y.A.; Minamisawa, S.; Berger, F.G.; Markwald, R.R.; Toole, B.P.; Ghatak, S. Hyaluronan constitutively regulates activation of COX-2-mediated cell survival activity in intestinal epithelial and colon carcinoma cells. J. Biol. Chem. 2008, 283, 14335-14344. [CrossRef] [PubMed]

103. Lv, L.; Liu, H.G.; Dong, S.Y.; Yang, F.; Wang, Q.X.; Guo, G.L.; Pan, Y.F.; Zhang, X.H. Upregulation of CD44v6 contributes to acquired chemoresistance via the modulation of autophagy in colon cancer SW480 cells. Tumor Biol. 2016, 37, 8811-8824. [CrossRef]

104. Chatterjee, M.; Rancso, C.; Stuhmer, T.; Eckstein, N.; Andrulis, M.; Gerecke, C.; Lorentz, H.; Royer, H.D.; Bargou, R.C. The Y-box binding protein $\mathrm{YB}-1$ is associated with progressive disease and mediates survival and drug resistance in multiple myeloma. Blood 2008, 111, 3714-3722. [CrossRef] [PubMed]

105. Dean, M.; Fojo, T.; Bates, S. Tumour stem cells and drug resistance. Nat. Rev. Cancer 2005, 5, 275-284. [CrossRef] [PubMed]

106. Dalerba, P.; Cho, R.W.; Clarke, M.F. Cancer stem cells: Models and concepts. Annu. Rev. Med. 2007, 58, 267-284. [CrossRef]

107. Horst, D.; Kriegl, L.; Engel, J.; Kirchner, T.; Jung, A. Prognostic significance of the cancer stem cell markers CD133, CD44, and CD166 in colorectal cancer. Cancer Invest. 2009, 27, 844-850. [CrossRef]

108. Hsu, P.D.; Lander, E.S.; Zhang, F. Development and applications of CRISPR-Cas9 for genome engineering. Cell 2014, 157, 1262-1278. [CrossRef]

109. Hsu, P.D.; Scott, D.A.; Weinstein, J.A.; Ran, F.A.; Konermann, S.; Agarwala, V.; Li, Y.; Fine, E.J.; Wu, X.; Shalem, O.; et al. DNA targeting specificity of RNA-guided Cas9 nucleases. Nat. Biotechnol. 2013, 31, 827-832. [CrossRef]

110. Yang, F.; Cui, P.; Lu, Y.; Zhang, X. Requirement of the transcription factor YB-1 for maintaining the stemness of cancer stem cells and reverting differentiated cancer cells into cancer stem cells. Stem Cell Res. Ther. 2019, 10, 233. [CrossRef]

111. Zhang, H.; Cheng, S.; Zhang, M.; Ma, X.; Zhang, L.; Wang, Y.; Rong, R.; Ma, J.; Xia, S.; Du, M.; et al. Prostaglandin E2 promotes hepatocellular carcinoma cell invasion through upregulation of YB-1 protein expression. Int. J. Oncol. 2014, 44, 769-780. [CrossRef] [PubMed]

112. Lakshman, M.; Subramaniam, V.; Rubenthiran, U.; Jothy, S. CD44 promotes resistance to apoptosis in human colon cancer cells. Exp. Mol. Pathol. 2004, 77, 18-25. [CrossRef] [PubMed] 
113. Lakshman, M.; Subramaniam, V.; Wong, S.; Jothy, S. CD44 promotes resistance to apoptosis in murine colonic epithelium. J. Cell Physiol. 2005, 203, 583-588. [CrossRef] [PubMed]

114. Dylla, S.J.; Beviglia, L.; Park, I.K.; Chartier, C.; Raval, J.; Ngan, L.; Pickell, K.; Aguilar, J.; Lazetic, S.; Smith-Berdan, S.; et al. Colorectal cancer stem cells are enriched in xenogeneic tumors following chemotherapy. PLoS ONE 2008, 3, e2428. [CrossRef]

115. Zhou, Y.; Xia, L.; Wang, H.; Oyang, L.; Su, M.; Liu, Q.; Lin, J.; Tan, S.; Tian, Y.; Liao, Q.; et al. Cancer stem cells in progression of colorectal cancer. Oncotarget 2018, 9, 33403-33415. [CrossRef] [PubMed]

116. Zhang, H.; Zhang, X.; Wu, X.; Li, W.; Su, P.; Cheng, H.; Xiang, L.; Gao, P.; Zhou, G. Interference of Frizzled 1 (FZD1) reverses multidrug resistance in breast cancer cells through the Wnt/beta-catenin pathway. Cancer Lett. 2012, 323, 106-113. [CrossRef]

117. Cheng, X.; Xu, X.; Chen, D.; Zhao, F.; Wang, W. Therapeutic potential of targeting the Wnt/beta-catenin signaling pathway in colorectal cancer. Biomed. Pharmacother. 2019, 110, 473-481. [CrossRef]

118. Nagahama, Y.; Ueno, M.; Miyamoto, S.; Morii, E.; Minami, T.; Mochizuki, N.; Saya, H.; Takakura, N. PSF1, a DNA replication factor expressed widely in stem and progenitor cells, drives tumorigenic and metastatic properties. Cancer Res. 2010, 70, 1215-1224. [CrossRef]

119. Kessenbrock, K.; Wang, C.Y.; Werb, Z. Matrix metalloproteinases in stem cell regulation and cancer. Matrix Biol. 2015, 44-46, 184-190. [CrossRef]

120. Lin, S.Y.; Makino, K.; Xia, W.; Matin, A.; Wen, Y.; Kwong, K.Y.; Bourguignon, L.; Hung, M.C. Nuclear localization of EGF receptor and its potential new role as a transcription factor. Nat. Cell Biol. 2001, 3, 802-808. [CrossRef]

121. Lee, J.L.; Wang, M.J.; Chen, J.Y. Acetylation and activation of STAT3 mediated by nuclear translocation of CD44. J. Cell Biol. 2009, 185, 949-957. [CrossRef] [PubMed]

122. Peng, H.; Moffett, J.; Myers, J.; Fang, X.; Stachowiak, E.K.; Maher, P.; Kratz, E.; Hines, J.; Fluharty, S.J.; Mizukoshi, E.; et al. Novel nuclear signaling pathway mediates activation of fibroblast growth factor-2 gene by type 1 and type 2 angiotensin II receptors. Mol. Biol. Cell 2001, 12, 449-462. [CrossRef] [PubMed]

123. Wang, S.C.; Lien, H.C.; Xia, W.; Chen, I.F.; Lo, H.W.; Wang, Z.; Ali-Seyed, M.; Lee, D.F.; Bartholomeusz, G.; Ou-Yang, F.; et al. Binding at and transactivation of the COX-2 promoter by nuclear tyrosine kinase receptor ErbB-2. Cancer Cell 2004, 6, $251-261$. [CrossRef]

124. Reilly, J.F.; Maher, P.A. Importin beta-mediated nuclear import of fibroblast growth factor receptor: Role in cell proliferation. J. Cell Biol. 2001, 152, 1307-1312. [CrossRef]

125. Miletti-Gonzalez, K.E.; Murphy, K.; Kumaran, M.N.; Ravindranath, A.K.; Wernyj, R.P.; Kaur, S.; Miles, G.D.; Lim, E.; Chan, R.; Chekmareva, M.; et al. Identification of function for CD44 intracytoplasmic domain (CD44-ICD): Modulation of matrix metalloproteinase 9 (MMP-9) transcription via novel promoter response element. J. Biol. Chem. 2012, 287, 18995-19007. [CrossRef] [PubMed]

126. Heckman, C.A.; Mehew, J.W.; Boxer, L.M. NF-kappaB activates Bcl-2 expression in t(14;18) lymphoma cells. Oncogene 2002, 21, 3898-3908. [CrossRef]

127. Smith, S.M.; Lyu, Y.L.; Cai, L. NF-kappaB affects proliferation and invasiveness of breast cancer cells by regulating CD44 expression. PLoS ONE 2014, 9, e106966. [CrossRef] [PubMed]

128. Lee, R.J.; Albanese, C.; Fu, M.; D’Amico, M.; Lin, B.; Watanabe, G.; Haines, G.K., III; Siegel, P.M.; Hung, M.C.; Yarden, Y.; et al. Cyclin D1 is required for transformation by activated Neu and is induced through an E2F-dependent signaling pathway. Mol. Cell. Biol. 2000, 20, 672-683. [CrossRef]

129. Kuwano, M.; Shibata, T.; Watari, K.; Ono, M. Oncogenic Y-box binding protein-1 as an effective therapeutic target in drug-resistant cancer. Cancer Sci. 2019, 110, 1536-1543. [CrossRef]

130. Takahashi, K.; Okita, K.; Nakagawa, M.; Yamanaka, S. Induction of pluripotent stem cells from fibroblast cultures. Nat. Protoc. 2007, 2, 3081-3089. [CrossRef]

131. Maherali, N.; Sridharan, R.; Xie, W.; Utikal, J.; Eminli, S.; Arnold, K.; Stadtfeld, M.; Yachechko, R.; Tchieu, J.; Jaenisch, R.; et al. Directly reprogrammed fibroblasts show global epigenetic remodeling and widespread tissue contribution. Cell Stem Cell 2007, 1, 55-70. [CrossRef] [PubMed]

132. Celesti, G.; Di Caro, G.; Bianchi, P.; Grizzi, F.; Basso, G.; Marchesi, F.; Doni, A.; Marra, G.; Roncalli, M.; Mantovani, A.; et al. Presence of Twist1-positive neoplastic cells in the stroma of chromosome-unstable colorectal tumors. Gastroenterology 2013, 145, 647-657.e15. [CrossRef] [PubMed]

133. Muller, M.; Hermann, P.C.; Liebau, S.; Weidgang, C.; Seufferlein, T.; Kleger, A.; Perkhofer, L. The role of pluripotency factors to drive stemness in gastrointestinal cancer. Stem Cell Res. 2016, 16, 349-357. [CrossRef]

134. Thiery, J.P.; Acloque, H.; Huang, R.Y.; Nieto, M.A. Epithelial-mesenchymal transitions in development and disease. Cell 2009, 139, 871-890. [CrossRef]

135. Fan, Y.L.; Zheng, M.; Tang, Y.L.; Liang, X.H. A new perspective of vasculogenic mimicry: EMT and cancer stem cells (Review). Oncol. Lett. 2013, 6, 1174-1180. [CrossRef]

136. Liu, Y.S.; Hsu, H.C.; Tseng, K.C.; Chen, H.C.; Chen, S.J. Lgr5 promotes cancer stemness and confers chemoresistance through ABCB1 in colorectal cancer. Biomed. Pharmacother. 2013, 67, 791-799. [CrossRef] [PubMed]

137. Izumi, D.; Ishimoto, T.; Miyake, K.; Eto, T.; Arima, K.; Kiyozumi, Y.; Uchihara, T.; Kurashige, J.; Iwatsuki, M.; Baba, Y.; et al Colorectal Cancer Stem Cells Acquire Chemoresistance Through the Upregulation of F-Box/WD Repeat-Containing Protein 7 and the Consequent Degradation of c-Myc. Stem Cells 2017, 35, 2027-2036. [CrossRef] [PubMed] 
138. Rodda, D.J.; Chew, J.L.; Lim, L.H.; Loh, Y.H.; Wang, B.; Ng, H.H.; Robson, P. Transcriptional regulation of nanog by OCT4 and SOX $_{2}$. J. Biol. Chem. 2005, 280, 24731-24737. [CrossRef]

139. De Carlo, F.; Witte, T.R.; Hardman, W.E.; Claudio, P.P. Omega-3 eicosapentaenoic acid decreases CD133 colon cancer stem-like cell marker expression while increasing sensitivity to chemotherapy. PLoS ONE 2013, 8, e69760. [CrossRef] [PubMed]

140. Wu, C.; Alman, B.A. Side population cells in human cancers. Cancer Lett. 2008, 268, 1-9. [CrossRef]

141. Challen, G.A.; Little, M.H. A side order of stem cells: The SP phenotype. Stem Cells 2006, 24, 3-12. [CrossRef] [PubMed]

142. Haraguchi, N.; Inoue, H.; Tanaka, F.; Mimori, K.; Utsunomiya, T.; Sasaki, A.; Mori, M. Cancer stem cells in human gastrointestinal cancers. Hum. Cell 2006, 19, 24-29. [CrossRef]

143. Xiong, B.; Ma, L.; Hu, X.; Zhang, C.; Cheng, Y. Characterization of side population cells isolated from the colon cancer cell line SW480. Int. J. Oncol. 2014, 45, 1175-1183. [CrossRef] [PubMed]

144. Chen, D. Tumor formation and drug resistance properties of human glioblastoma side population cells. Mol. Med. Rep. 2015, 11, 4309-4314. [CrossRef]

145. Melo, F.d.S.e.; Kurtova, A.V.; Harnoss, J.M.; Kljavin, N.; Hoeck, J.D.; Hung, J.; Anderson, J.E.; Storm, E.E.; Modrusan, Z.; Koeppen, H.; et al. A distinct role for Lgr5(+) stem cells in primary and metastatic colon cancer. Nature 2017, 543, 676-680. [CrossRef] [PubMed]

146. Bu, Y.; Cao, D. The origin of cancer stem cells. Front. Biosci. 2012, 4, 819-830.

147. Schuijers, J.; Clevers, H. Adult mammalian stem cells: The role of Wnt, Lgr5 and R-spondins. EMBO J. 2012, 31, 2685-2696. [CrossRef]

148. Sterlacci, W.; Savic, S.; Fiegl, M.; Obermann, E.; Tzankov, A. Putative stem cell markers in non-small-cell lung cancer: A clinicopathologic characterization. J. Thorac. Oncol. 2014, 9, 41-49. [CrossRef]

149. Gupta, P.B.; Chaffer, C.L.; Weinberg, R.A. Cancer stem cells: Mirage or reality? Nat. Med. 2009, 15, 1010-1012. [CrossRef]

150. Valastyan, S.; Weinberg, R.A. Tumor metastasis: Molecular insights and evolving paradigms. Cell 2011, 147, 275-292. [CrossRef]

151. Gupta, G.P.; Massague, J. Cancer metastasis: Building a framework. Cell 2006, 127, 679-695. [CrossRef] [PubMed]

152. Steeg, P.S. Tumor metastasis: Mechanistic insights and clinical challenges. Nat. Med. 2006, 12, 895-904. [CrossRef] [PubMed]

153. Bonnet, D.; Dick, J.E. Human acute myeloid leukemia is organized as a hierarchy that originates from a primitive hematopoietic cell. Nat. Med. 1997, 3, 730-737. [CrossRef] [PubMed]

154. Dalerba, P.; Dylla, S.J.; Park, I.K.; Liu, R.; Wang, X.; Cho, R.W.; Hoey, T.; Gurney, A.; Huang, E.H.; Simeone, D.M.; et al. Phenotypic characterization of human colorectal cancer stem cells. Proc. Natl. Acad. Sci. USA 2007, 104, 10158-10163. [CrossRef] [PubMed]

155. Basu, S.; Haase, G.; Ben-Ze'ev, A. Wnt signaling in cancer stem cells and colon cancer metastasis. F1000Res 2016, 5, 1-10. [CrossRef]

156. Cleophas, M.C.; Joosten, L.A.; Stamp, L.K.; Dalbeth, N.; Woodward, O.M.; Merriman, T.R. ABCG2 polymorphisms in gout: Insights into disease susceptibility and treatment approaches. Pharmgenomics Pers. Med. 2017, 10, 129-142. [CrossRef] [PubMed]

157. Gao, W.; Chen, L.; Ma, Z.; Du, Z.; Zhao, Z.; Hu, Z.; Li, Q. Isolation and phenotypic characterization of colorectal cancer stem cells with organ-specific metastatic potential. Gastroenterology 2013, 145, 636-646.e5. [CrossRef]

158. Malanchi, I.; Santamaria-Martinez, A.; Susanto, E.; Peng, H.; Lehr, H.A.; Delaloye, J.F.; Huelsken, J. Interactions between cancer stem cells and their niche govern metastatic colonization. Nature 2011, 481, 85-89. [CrossRef]

159. Wang, Z.; Ouyang, G. Periostin: A bridge between cancer stem cells and their metastatic niche. Cell Stem Cell 2012, 10, 111-112. [CrossRef]

160. Zeuner, A.; Todaro, M.; Stassi, G.; De Maria, R. Colorectal cancer stem cells: From the crypt to the clinic. Cell Stem Cell 2014, 15, 692-705. [CrossRef]

161. You, L.; Guo, X.; Huang, Y. Correlation of Cancer Stem-Cell Markers OCT4, SOX 2 , and NANOG with Clinicopathological Features and Prognosis in Operative Patients with Rectal Cancer. Yonsei Med. J. 2018, 59, 35-42. [CrossRef] [PubMed]

162. Miyoshi, N.; Ishii, H.; Nagai, K.; Hoshino, H.; Mimori, K.; Tanaka, F.; Nagano, H.; Sekimoto, M.; Doki, Y.; Mori, M. Defined factors induce reprogramming of gastrointestinal cancer cells. Proc. Natl. Acad. Sci. USA 2010, 107, 40-45. [CrossRef] [PubMed]

163. Kong, D.; Li, Y.; Wang, Z.; Sarkar, F.H. Cancer Stem Cells and Epithelial-to-Mesenchymal Transition (EMT)-Phenotypic Cells: Are They Cousins or Twins? Cancers 2011, 3, 716-729. [CrossRef] [PubMed]

164. Hutz, K.; Mejias-Luque, R.; Farsakova, K.; Ogris, M.; Krebs, S.; Anton, M.; Vieth, M.; Schuller, U.; Schneider, M.R.; Blum, H.; et al. The stem cell factor $\mathrm{SOX}_{2}$ regulates the tumorigenic potential in human gastric cancer cells. Carcinogenesis 2014, 35, 942-950. [CrossRef]

165. Hoffman, B.; Liebermann, D.A. Apoptotic signaling by c-MYC. Oncogene 2008, 27, 6462-6472. [CrossRef]

166. Takahashi, A.; Ohtani, N.; Yamakoshi, K.; Iida, S.; Tahara, H.; Nakayama, K.; Nakayama, K.I.; Ide, T.; Saya, H.; Hara, E. Mitogenic signalling and the p16INK4a-Rb pathway cooperate to enforce irreversible cellular senescence. Nat. Cell Biol. 2006, 8, $1291-1297$. [CrossRef]

167. Avery, S.; Inniss, K.; Moore, H. The regulation of self-renewal in human embryonic stem cells. Stem Cells Dev. 2006, 15, 729-740. [CrossRef]

168. Masui, S.; Nakatake, Y.; Toyooka, Y.; Shimosato, D.; Yagi, R.; Takahashi, K.; Okochi, H.; Okuda, A.; Matoba, R.; Sharov, A.A.; et al. Pluripotency governed by Sox 2 via regulation of Oct3/4 expression in mouse embryonic stem cells. Nat. Cell Biol. 2007, 9, 625-635. [CrossRef] 
169. Aoi, T.; Yae, K.; Nakagawa, M.; Ichisaka, T.; Okita, K.; Takahashi, K.; Chiba, T.; Yamanaka, S. Generation of pluripotent stem cells from adult mouse liver and stomach cells. Science 2008, 321, 699-702. [CrossRef]

170. Yu, J.; Vodyanik, M.A.; Smuga-Otto, K.; Antosiewicz-Bourget, J.; Frane, J.L.; Tian, S.; Nie, J.; Jonsdottir, G.A.; Ruotti, V.; Stewart, R.; et al. Induced pluripotent stem cell lines derived from human somatic cells. Science 2007, 318, 1917-1920. [CrossRef]

171. De Giovanni, C.; Landuzzi, L.; Nicoletti, G.; Astolfi, A.; Croci, S.; Micaroni, M.; Nanni, P.; Lollini, P.L. Apc10.1: An ApcMin/+ intestinal cell line with retention of heterozygosity. Int. J. Cancer 2004, 109, 200-206. [CrossRef] [PubMed]

172. Cong, L.; Zhang, F. Genome engineering using CRISPR-Cas9 system. Methods Mol. Biol. 2015, 1239, 197-217. [PubMed]

173. Jin, J.; Xu, Y.; Huo, L.; Ma, L.; Scott, A.W.; Pizzi, M.P.; Li, Y.; Wang, Y.; Yao, X.; Song, S.; et al. An improved strategy for CRISPR/Cas9 gene knockout and subsequent wildtype and mutant gene rescue. PLoS ONE 2020, 15, e0228910. [CrossRef] [PubMed]

174. Ghatak, S.; Bogatkevich, G.S.; Atnelishvili, I.; Akter, T.; Feghali-Bostwick, C.; Hoffman, S.; Fresco, V.M.; Fuchs, J.C.; Visconti, R.P.; Markwald, R.R.; et al. Overexpression of c-Met and CD44v6 receptors contributes to autocrine TGF-beta1 signaling in interstitial lung disease. J. Biol. Chem 2014, 289, 7856-7872. [CrossRef] [PubMed]

175. Ghatak, S.; Hascall, V.C.; Markwald, R.R.; Misra, S. Stromal hyaluronan interaction with epithelial CD44 variants promotes prostate cancer invasiveness by augmenting expression and function of hepatocyte growth factor and androgen receptor. J. Biol. Chem. 2010, 285, 19821-19832. [CrossRef] [PubMed]

176. Ghatak, S.; Misra, S.; Norris, R.A.; Moreno-Rodriguez, R.A.; Hoffman, S.; Levine, R.A.; Hascall, V.C.; Markwald, R.R. Periostin induces intracellular cross-talk between kinases and hyaluronan in atrioventricular valvulogenesis. J. Biol. Chem. 2014, 289, 8545-8561. [CrossRef]

177. Andoorfar, S.; Tafreshi, S.A.H.; Rezvani, Z. Assessment of the expression level of miRNA molecules using a semi-quantitative RT-PCR approach. Mol. Biol. Rep. 2019, 46, 5057-5062. [CrossRef]

178. Finkbeiner, M.R.; Astanehe, A.; To, K.; Fotovati, A.; Davies, A.H.; Zhao, Y.; Jiang, H.; Stratford, A.L.; Shadeo, A.; Boccaccio, C.; et al. Profiling YB-1 target genes uncovers a new mechanism for MET receptor regulation in normal and malignant human mammary cells. Oncogene 2009, 28, 1421-1431. [CrossRef] 